\title{
Towards a Smarter Battery Management System for Electric Vehicle Applications: A Critical Review of Lithium-Ion Battery State of Charge Estimation
}

\author{
Muhammad Umair Ali ${ }^{1}{ }^{\circledR}$, Amad Zafar $^{2}{ }^{\circledR}$, Sarvar Hussain Nengroo ${ }^{1}{ }^{\circledR}$, Sadam Hussain ${ }^{1}$, \\ Muhammad Junaid Alvi ${ }^{3}$ and Hee-Je Kim ${ }^{1, *}$ \\ 1 School of Electrical Engineering, Pusan National University, San 30, ChangJeon 2 Dong, KeumJeong-gu, \\ Pusan 46241, Korea; umairali.m99@gmail.com (M.U.A.); ssarvarhussain@gmail.com (S.H.N.); \\ sadamengr15@gmail.com (S.H.) \\ 2 Department of Electrical Engineering, Wah Engineering College, University of Wah, Wah \\ Cantt 47040, Pakistan; amad@pusan.ac.kr \\ 3 Department of Electrical Engineering, University of Engineering and Technology, Lahore 54890, Pakistan; \\ alvi_junaid@yahoo.com \\ * Correspondence: heeje@pusan.ac.kr; Tel.: +82-51-510-2364
}

Received: 4 January 2019; Accepted: 29 January 2019; Published: 30 January 2019

\begin{abstract}
Energy storage system (ESS) technology is still the logjam for the electric vehicle (EV) industry. Lithium-ion (Li-ion) batteries have attracted considerable attention in the EV industry owing to their high energy density, lifespan, nominal voltage, power density, and cost. In EVs, a smart battery management system (BMS) is one of the essential components; it not only measures the states of battery accurately, but also ensures safe operation and prolongs the battery life. The accurate estimation of the state of charge (SOC) of a Li-ion battery is a very challenging task because the Li-ion battery is a highly time variant, non-linear, and complex electrochemical system. This paper explains the workings of a Li-ion battery, provides the main features of a smart BMS, and comprehensively reviews its SOC estimation methods. These SOC estimation methods have been classified into four main categories depending on their nature. A critical explanation, including their merits, limitations, and their estimation errors from other studies, is provided. Some recommendations depending on the development of technology are suggested to improve the online estimation.
\end{abstract}

Keywords: battery management system; energy storage system; electric vehicle; lithium-ion battery; state of charge

\section{Introduction}

The global reserves of diesel, petrol, and other fossil fuels are decreasing rapidly due to their extensive use in transportation operation. The far-flung use of the traditional fuels produces tons of $\mathrm{CO}_{2}$ yearly, which have harmful implications for the environment, such as greenhouse gas emissions (GHGE) and global warming [1]. In addition, the costs of these fuels are increasing exponentially, so there is a need for a secondary energy source for transportation, such as electric vehicles (EVs), new energy vehicles (NEVs), plug-in hybrid electric vehicle (PHEVs), battery electric vehicles (BEVs), and fuel cell electric vehicles (FCEVs) [2,3]. In recent years, rechargeable batteries (RBs) have attracted considerable attention owing to their high demand in EVs, HEVs, and PHEVs [4-7]. With the use of renewable energy, these transportation sources can reduce their GHGE by up to $40 \%$ [8]. The alternative energy sources, such as wave, wind, tidal, and solar, are episodical, so these energy resources also require an energy storage system (ESS) to maintain a smooth and reliable supply to the consumer [9]. 
In recent years, United States, Japan, China, and Germany have taken keen interest in the performance improvement of RBs and accomplished some significant results [10].

Different energy storage systems, such as lead-acid, lithium ion (Li-ion), sodium nickel chloride $(\mathrm{NaNiCl})$, vanadium redox flow battery (VRFB), nickel cadmium (NiCd), zinc bromine flow battery (ZBFB), and sodium sulphur (NaS) batteries have been widely accepted for transportation in recent years [11]. Among them, the Li-ion battery offers high reliability, high power density, long lifespan, high energy density, low discharge rate, and high efficiency [3]. In addition, the cost of Li-ion batteries is declining, which enhances their use in the EV industry [12] and therefore, the Li-ion battery market is growing [13].

An efficient battery management system (BMS) is one of the primary components in EVs to guarantee the safe, reliable, efficient, and long-lasting operation of a Li-ion battery while dealing with the electric grid and challenging driving conditions [14-16]. Furthermore, an efficient BMS also provides information on the battery states, such as the state of available power (SOP), state of charge (SOC), state of life (SOL), and state of health (SOH). The BMS can sense the battery voltage, battery current, and temperature to avoid overcharge and over discharge conditions. These measured parameters can be utilized to estimate the states of the Li-ion battery $[15,16]$.

Accurate SOC estimations have always been a critical and important concern in the design of BMS in EVs. Accurate and precise estimations can not only be used to evaluate the reliability of a battery, but also provide some important information, such as the remaining energy and/or remaining useable time [17]. In other words, the SOC shows the vehicle driving range or the remaining power of the battery in EVs. Furthermore, it prevents the Li-ion battery from over- charge/discharge. The Li-ion battery is a highly complex, time varying and nonlinear electrochemical system; its performance changes due to different factors, such as the charge-discharge current, aging, and temperature variations. Therefore, accurate SOC estimation of Li-ion battery is a tricky task because it cannot be directly assessed using any physical sensor [18]. Currently, the Li-ion battery SOC estimation is a hot topic for researchers. An assortment of SOC estimation techniques has been reported over the last decade. Figure 1 shows the trend of research articles published on SOC estimations for Li-ion batteries.

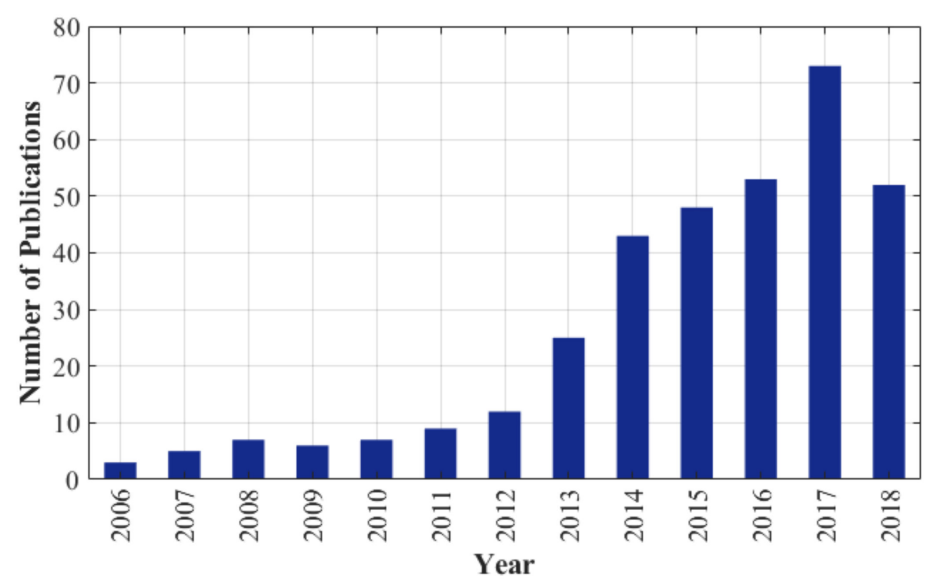

Figure 1. Number of publications on SOC estimation of Li-ion batteries per year.

These published research articles were found using the Web of Science database (http: / isiknowledge. com). The search criterion was the "state of charge" then "lithium ion battery" from 2006 to August 2018. Figure 1 highlights the considerable interest in Li-ion battery SOC estimations in recent years.

This review paper discusses working and advantages of the Li-ion battery in EVs over other energy storage systems. The general working of an effective BMS is presented in detail. This review paper classifies the reported Li-ion battery SOC estimation techniques in different categories according to their nature. This review also discusses their respective advantages and limitations. Finally, future perspectives and recommendations are presented. 


\section{Energy Storage Systems for EVs}

EVs consist of four main parts: an energy storage system (battery), mechanical transmission system, motor, and power converter [19]. Many energy storage systems are available, such as lead-acid, $\mathrm{NaS}, \mathrm{NaNiCl}, \mathrm{NiCd}, \mathrm{VRFB}, \mathrm{ZBFB}$, and Li-ion. Table 1 lists the properties of the aforementioned batteries. Only ambient temperature batteries have been considered in EVs for safe and reliable operation.

Table 1. Properties of the different types of energy storage systems [20].

\begin{tabular}{|c|c|c|c|c|c|c|c|}
\hline Battery Type & $\begin{array}{c}\text { Energy Density } \\
(\mathrm{Wh} / \mathrm{L})\end{array}$ & $\begin{array}{l}\text { Power Density } \\
\text { (W/L) }\end{array}$ & $\begin{array}{l}\text { Nominal Voltage } \\
\text { (V) }\end{array}$ & Life Cycle & $\begin{array}{c}\text { Depth of Discharge } \\
(\%)\end{array}$ & $\begin{array}{c}\text { Round Trip Efficiency } \\
(\%)\end{array}$ & $\begin{array}{l}\text { Estimated Cost } \\
\text { (USD/kWh) }\end{array}$ \\
\hline $\mathrm{NaS}$ & $140-300$ & $140-180$ & 2.08 & 5000 & 100 & 80 & 263-735 \\
\hline $\mathrm{NaNiCl}$ & $160-275$ & $150-270$ & - & 3000 & 100 & 84 & 315-488 \\
\hline VRFB & $25-33$ & $1-2$ & 1.4 & 13,000 & 100 & 70 & $315-1050$ \\
\hline ZBFB & $55-65$ & $1-25$ & 1.8 & 10,000 & 100 & 70 & $525-1680$ \\
\hline Li-ion & $200-400$ & $1500-10,000$ & 4.3 & 10,000 & 95 & 96 & $200-1260$ \\
\hline
\end{tabular}

Table 1 shows that among all the storage devices, the VRFB has the highest life cycle. The Li-ion battery has the highest energy and power densities as compared to the others. In addition, the cost, life cycle, and nominal voltage of the battery are also critical factors. The nominal voltage of a cell is a critical point because it decides the quantity of single cells required in a battery pack for safe and reliable operation. The Li-ion battery appears to be a better option because of its energy density, lifespan, nominal voltage, power density, and cost. Figure 2 presents a spider chart of the different cell chemistries for a better understanding and comparison [6].

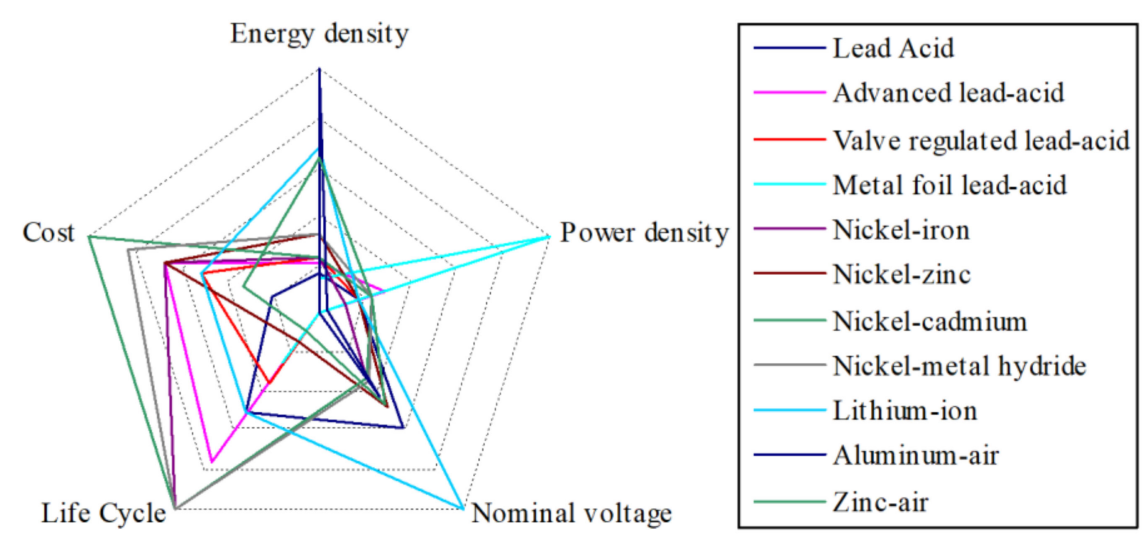

Figure 2. Spider chart for the different battery chemistries.

\section{Lithium Ion Battery}

Figure 3 presents the simplified working diagram of a Li-ion battery. The Li-ion cell is made of a positive electrode (anode), negative electrode (cathode), a separator, and two current collectors. $\mathrm{Li}^{+}$is transferred from the anode to the cathode through an electrolytic separator to complete the discharging cycle. The negative electrode is generally formulated from graphite and the anode general contains one of the following materials: Li-ion manganese oxide (LMO), Li-iron-phosphate (LFP), and Li-nickel-manganese-cobalt-oxide (LNMC). Diethyl carbonate or ethylene carbonate are used as the electrolyte. Aluminum and copper are used as positive and negative current collectors, respectively. The chemical reactions of $\mathrm{LMO} /$ graphite are reported as an example of both charging discharging.

For charging:

$$
\begin{gathered}
\mathrm{Li}_{\mathrm{b}} \mathrm{Mn}_{2} \mathrm{O}_{4} \rightarrow \mathrm{Li}_{\mathrm{b}-\mathrm{a}} \mathrm{Mn}_{2} \mathrm{O}_{4}+\mathrm{aLi}^{+}+\mathrm{ae}^{-} \\
\mathrm{Li}_{0} \mathrm{C}_{6}+\mathrm{aLi}^{+}+\mathrm{ae}^{-} \rightarrow \mathrm{Li}_{\mathrm{x}} \mathrm{C}_{6}
\end{gathered}
$$

For discharging:

$$
\mathrm{Li}_{\mathrm{b}-\mathrm{a}} \mathrm{Mn}_{2} \mathrm{O}_{4}+\mathrm{aLi}^{+}+\mathrm{ae}^{-} \rightarrow \mathrm{Li}_{\mathrm{b}} \mathrm{Mn}_{2} \mathrm{O}_{4}
$$




$$
\mathrm{Li}_{\mathrm{x}} \mathrm{C}_{6} \rightarrow \mathrm{Li}_{0} \mathrm{C}_{6}+\mathrm{aLi}^{+}+\mathrm{ae}^{-}
$$

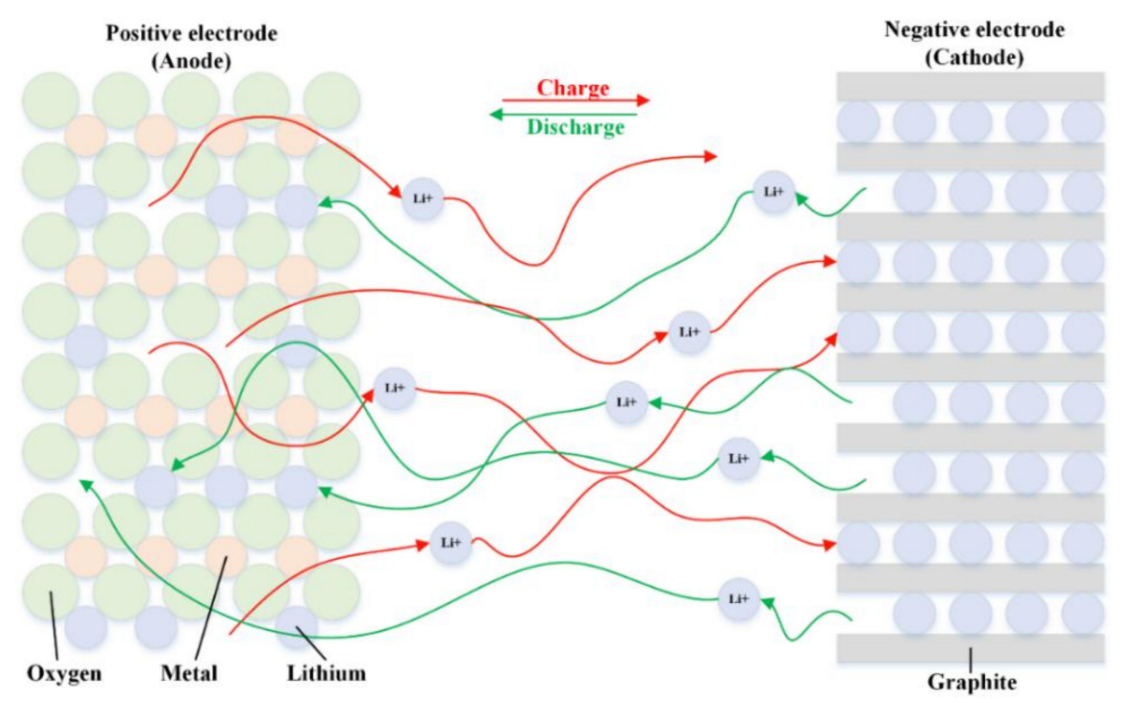

Figure 3. Schematic diagram of the Li-ion battery during the charging and discharging condition.

Different chemistries of Li-ion battery have been reported in the literature [21-24]. Table 2 compares the different types of Li-ion battery.

Table 2. Properties of the different types of Li-ion battery [10].

\begin{tabular}{|c|c|c|c|c|c|c|}
\hline Type & $\begin{array}{l}\text { Energy Density } \\
\text { (Wh/kg) }\end{array}$ & $\begin{array}{l}\text { Power Density } \\
\text { (W/kg) }\end{array}$ & $\begin{array}{c}\text { Life Cycle } \\
\text { (100\% DOD) }\end{array}$ & $\begin{array}{l}\text { Estimated Cost } \\
\text { (US\$/kWh) }\end{array}$ & Safety & Maturity \\
\hline LMO & 160 & 200 & $\geq 2000$ & $\sim 360$ & Good & Commercial \\
\hline LFP & 120 & 200 & $>2500$ & $\sim 360$ & Good & Commercial \\
\hline Li-titanate oxide & 70 & 1000 & $\geq 10,000$ & $\sim 860$ & Good & Demo \\
\hline Li-sulfur & 500 & - & $\sim 100$ & - & Good & R\&D stage \\
\hline
\end{tabular}

Although Li-ion battery is the best choice for EVs, it still needs a reduction in its capital cost along with improving performance and high life cycle. The reduction in its capital cost can be achieved in different ways, such as manufacturing and technology perspectives. A lot of efforts have been made to improve the round-trip efficiency and depth of discharge of Li-ion battery. According to a report, the reduction in the capital cost of Li-ion battery will be 77-574 USD/kWh from 200-1260 USD/kWh, the improvement in the energy density will be $200-735 \mathrm{Wh} / \mathrm{L}$, and the round-trip efficiency will increase $2 \%$ till 2030 [20].

\section{Battery Management System (BMS) for EVs}

After substantial progress in ESS, an effective and reliable BMS is needed. According to the most adopted definition, a BMS is a system that is capable of managing a battery [15]. The BMS in EVs consists of different types of sensors, actuators, and controllers. An efficient BMS performs the following main tasks: (i) protects the battery; (ii) operates the battery with a safe limit of current, voltage and temperature; and (iii) measures and estimates the battery states precisely. Figure 4 presents a schematic diagram of an efficient BMS.

The voltage and current measurement unit is installed to measure the voltages and currents of the entire string as well as that of a single cell. The temperature control unit is added to measure the temperature of the battery and coolant. The cooling and heating system can be controlled through this unit. This system also contains some analogue and digital inputs, such as an accelerating pedal sensor, brake pedal sensor, charging control, and engine ON/OFF switch. The balancing control unit consists of power dissipation resistors and capacitors. This is used to equalize the SOC of the cells in 
battery packs. The safety unit is used to avoid physical damage to the battery packs. The system also protects the battery packs from overcharge and over-discharge conditions. The digital output of the BMS contains the SOC, $\mathrm{SOH}$, balancing work indicator, and failure alarm. Considering the non-linear and inconsistent behavior of a battery, a precise and accurate SOC estimation is a difficult task. For a comprehensive diagram of an effective BMS, see Figure A1 of Appendix A.

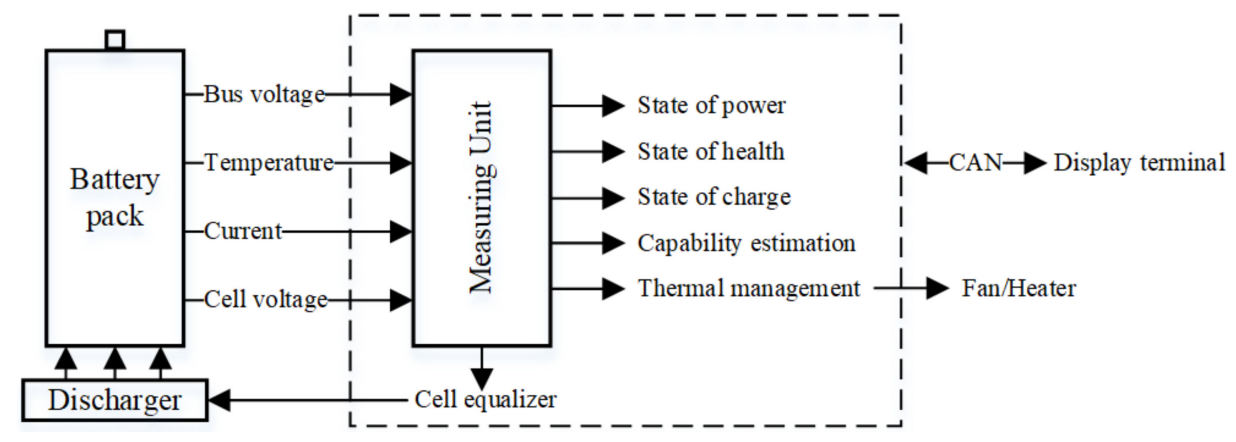

Figure 4. General diagram of a BMS.

\section{Methods to Estimate SOC}

As discussed earlier, an accurate SOC estimation is the most crucial part of the BMS design in EVs. This not only provides information on the useful energy, but also prevents the battery from over charge/discharge condition. Therefore, the SOC estimation has attracted considerable interest, and different methods have been presented in the literature, to estimate the SOC accurately and precisely. In the present study, the estimation methods are classified into four main categories, as shown in Figure 5 . The direct measurement method estimates the SOC using the physical properties. Book keeping estimation methods use the battery charge and discharge current as an input. In model-based methods, the battery parameters and SOC are estimated using adaptive filters and observers. The last methods are based purely on computer intelligence; they require high computational time and storage size.

The mean average error (MAE), maximum error (ME), and root mean square error (RMSE) can be utilized to quantitatively appraise the performance of different SOC estimation methods. The difference between the true and estimated value in continuous variables over the total number of samples is known as MAE. The RMSE can be calculated by taking square root of the average of squared difference between the true and estimated values in continuous variables. The mathematical forms of MAE and RMSE can be expressed as:

$$
\begin{gathered}
\text { MAE }=\frac{1}{n} \sum_{i=1}^{n}(\text { true value }- \text { predicted value }) \\
\text { RMSE }=\sqrt{\frac{1}{n} \sum_{i=1}^{n}(\text { true value }- \text { predicted value })^{2}}
\end{gathered}
$$

In Tables 3-21 the MAE and ME have been utilized to compare the results of different approaches. The computational complexity of all the methods cannot be compared because every operating system has different specs. The advantages and disadvantages of each method will be discussed in next section. 


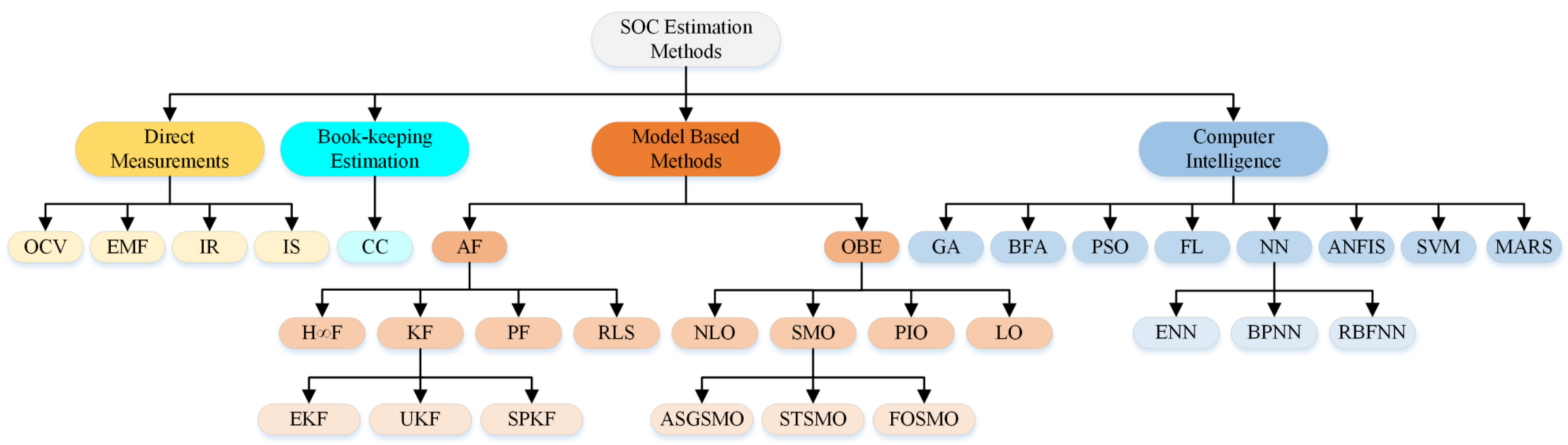

AF: Adaptive filters, ANFIS: Adaptive neuro fuzzy inference system, ASGSMO: Adaptive switching gain sliding mode observer, BFA: Bacterial foraging algorithm, BPNN: Backpropagation neural network, CC: Coulomb counting, EMF: Electromotive force, ENN: Elman neural network, EKF: Extended kalman Filter, FL: Fuzzy logic, FOSMO: Fractional order sliding mode observer, GA: Genetic algorithm, HœF: H infinity filter, IR: Internal resistance, IS: Impedance spectroscopy, KF: Kalman filter, MARS: Multivariate adaptive regression splines, LO: Luenberger-based observer. NLO: Nonlinear observer. NN: Neural network. OBE: Observer based estimation. OCV: Open circuit voltage, PF: Particle filter. PIO Proportional integral observer, PSO: Particle swarm optimization, RLS: Recursive least square filter, RBFNN: Radial basis function neural network, SPKF: Sigma point kalman filter, SVM: Support vector machine, SMO: Sliding mode observer, STSMO: Super twisting sliding mode observer, UKF: Unscented kalman filter.

Figure 5. Classification of the SOC estimation methods. 


\subsection{Direct Measurements}

A direct measurement SOC estimation method can be classified into the following four categories: electromotive force (EMF) method, impedance spectroscopy (IS) method, internal resistance (IR) method, and open circuit voltage $(\mathrm{OCV})$ method. An explanation of each category is presented in their relative section. Table 3 provides the estimation errors summary of all direct SOC methods at the end of Section 4.1.

\subsubsection{Open Circuit Voltage (OCV)}

The OCV method can be utilized to measure the SOC after an adequate pause to allow the battery to reach the equilibrium state. The Karhunen-Loeve expansion and linear regression method were used to predict the OCV curves at different charging currents [25]. The relationship between the SOC and OCV vary from battery to battery [26]. This method is very simple and highly accurate, but it needs long resting time to reach the equilibrium state. The resting time also depends on the environmental conditions. Moreover, careful measurements of the voltages are required due to the hysteresis characteristics of the battery [27]. This method is generally used in laboratories or as calibration auxiliary technology $[28,29]$.

Figure 6 shows the working cycle of the OCV method. Initially, fully charge the Li-ion battery and then relax it for a fixed time to depolarize. After depolarization, discharge the Li-ion using current pulses until its full discharge, relax the battery for a fixed interval after each interval to depolarize and then measure the OCV of the Li-ion battery. The same process has to perform to measure OCV during charging mode.

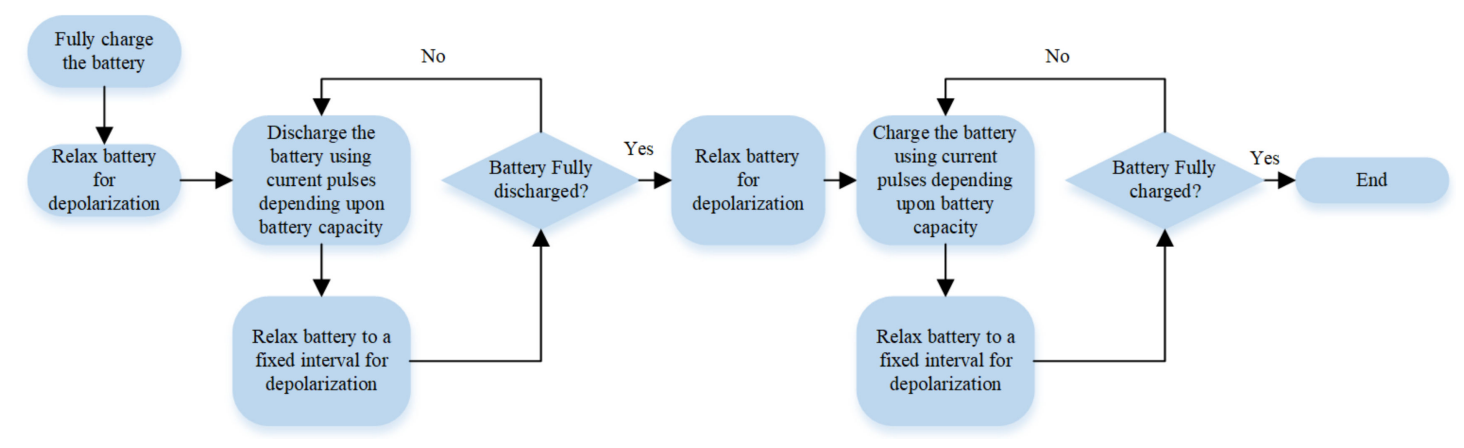

Figure 6. Working cycle of OCV-SOC estimation methods.

\subsubsection{Electromotive Force (EMF)}

The SOC can also be measured using the EMF of the Li-ion battery. The EMF can be determined to be the OCV when the battery is in equilibrium. The EMF is associated with the battery SOC. The OCV using the EMF was modeled using different methods [30-32]. The SOC was then determined using the modeled OCV value. Coleman et al. [31] proposed a model to predict the EMF voltage for a SOC estimation. The authors divided the battery's voltage curve into two parts. The first part contained the linear region (full to partial SOC) and other has a hyperbolic region (partial to low SOC) of the curve. In this method, the EMF was estimated using the load current and terminal voltage with some coefficients for the linear region, impedance, and the terminal voltage; the battery current was considered for the hyperbolic region. This model showed good results for a SOC estimation. Similarly, another study [32] presented an approach to estimate the EMF by considering the short OCV relaxation time after battery current stoppage. The proposed model has an EMF source with a parallel resistance and a constant phase element. The EMF was estimated using the battery current and terminal voltage. The algorithm took some time after interrupting the current to determine the EMF of the battery. 


\subsubsection{Internal Resistance (IR)}

This SOC estimation method used the battery charging/discharging current and terminal voltage to estimate the resistance of the Li-ion battery, which is also known as the DC resistance. The terminal voltage was measured with the change in current for a small interval of less than 10 milliseconds [33]. This small-time duration was always set to minimize the transfer reaction and acid diffusion effect; a large time duration is associated with some error. This method is highly accurate at the end points of the discharge. Recently, a direct current short pulse (DCSP) method has been proposed to determine the IR [34]. The value of the resistance is very low which is challenging to measure [15]. Therefore, this method is not a good choice for SOC estimation.

\subsubsection{Impedance Spectroscopy (IS)}

The internal impedance can be utilized to characterize a Li-ion battery under different conditions. IS was applied to measure the SOC of a Li-ion battery. In the IS method, different current frequencies are applied across the Li-ion battery to determine the impedance [35-38]. Once the internal impedance is known, it can be plotted easily against the SOC. IS method can also be used for online SOC estimation [39]. Different studies that used IS method for the SOC estimation are shown in Table 3.

Table 3. MAE of the direct SOC estimation methods.

\begin{tabular}{clc}
\hline Method & \multicolumn{1}{c}{ Reference } & MAE (\%) \\
\hline \multirow{2}{*}{ OCV } & Truchot et al. 2014 [28] & $\begin{array}{c}\text { Unspecified } \\
\leq \pm 1.2 \%\end{array}$ \\
& V. Pop et al. 2006 [29] & $\leq \pm 2 \%$ \\
\hline \multirow{2}{*}{ EMF } & Waag and Sauer. 2013 [32] & Unspecified \\
IR & Wang and Liu. 2013 [33] & $\leq \pm 1.4 \%$ \\
\hline \multirow{2}{*}{ IS } & Bao et al. 2018 [34] & Unspecified \\
& Coleman et al. 2007 [31] & $\leq \pm 1 \%$ \\
& Xu et al. 2013 [37] & $\leq \pm 2.75 \%$ \\
& Westerhoff et al. 2016 [36] & $\leq \pm 4 \%$ \\
\hline
\end{tabular}

\subsection{Book-Keeping Estimations}

\section{Coulomb Counting (CC)}

The CC method is based purely on the battery charging or discharging current. This method integrates the battery charging or discharging current over time to find SOC [40]. The mathematical form of the CC method can be expressed as:

$$
\operatorname{SOC}(t)=\operatorname{SOC}\left(t_{o}\right)-\frac{1}{Q} \int_{t_{0}}^{t}\left(\eta \cdot i_{b a t}(t)-s_{d}\right) d t
$$

where $\operatorname{SOC}\left(t_{0}\right)$ and $\operatorname{SOC}(t)$ are the SOCs at initial time and sampling time $t$ respectively; $\eta$ is the Columbic efficiency; $i_{b a t}(t)$ is the instantaneous charging or discharging current (+ve for discharging and -ve for charging); $s_{d}$ is the self-discharge rate, and $Q$ is the nominal capacity. The implementation of this method is quite simple with very low computational complexity. The initial unknown SOC is the main concern in the CC. Moreover, the sensor error also has a negative effect on the accuracy of the SOC estimation. Therefore, this method works more efficiently, where the SOC needs to be estimated for the short period and the initial SOC is known [40]. Table 4 provides the estimation error summary of the bookkeeping estimation method [41-45]. 
Table 4. MAE/ME of the CC SOC estimation method.

\begin{tabular}{lc}
\hline \multicolumn{1}{c}{ Reference } & MAE (\%) \\
\hline Zhang et al. 2014 [41] & $\leq \pm 4 \%$ \\
Wu et al. 2017 [42] & $\leq \pm 1.905 \%$ \\
Xie et al. 2018 [43] & $\mathrm{ME} \leq \pm 2.69 \%$ \\
Xu et al. 2009 [44] & $\mathrm{ME} \leq \pm 6.5 \%$ \\
Cheng et al. 2011 [45] & Unspecified \\
\hline
\end{tabular}

\subsection{Model-Based Methods}

The aforementioned conventional methods have some issues related to their efficiency and high estimation accuracy in real time. Model-based SOC estimation methods overcome the deficiencies of the conventional methods. Model-based methods use the Li-ion battery parameters to deploy the battery model and then estimate its SOC using some advanced algorithms. The electrochemical model (EChM) [46-50] and equivalent circuit model (ECM) [50-53] are the most commonly used model for the Li-ion battery. For further details on the type of battery models, merits, and demerits, see Rivera-Barrera et al. [40]. Figure 7 presents a general diagram of the model-based SOC estimation methods. The voltage, current and, the temperature has been measured to model the Li-ion battery. The difference between the estimated and true voltage value generated the error signal. The model-based methods utilized this error signal to estimate the SOC of the Li-ion battery. The model-based estimation methods are discussed herein separately in the subsequent sections.

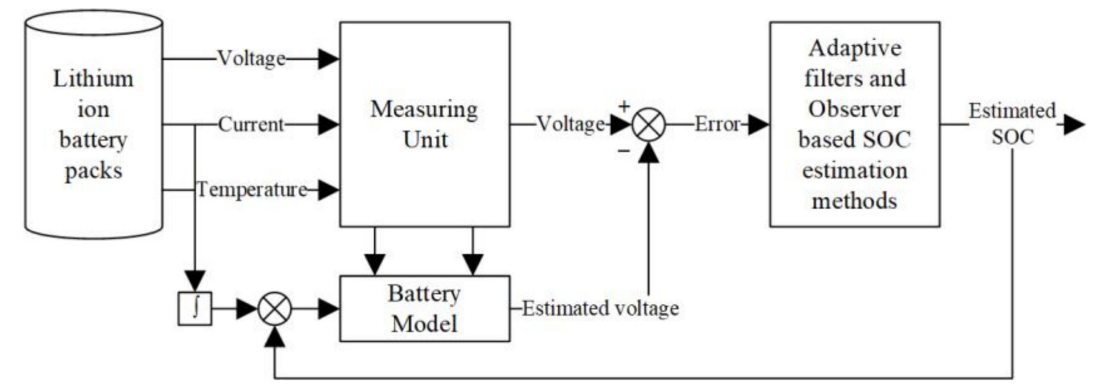

Figure 7. General diagram of model-based SOC estimation methods.

\subsubsection{Adaptive Filters (AF)}

The adaptive filtering (AF) algorithm has been used frequently in model-based SOC estimations of Li-ion batteries. The AF algorithm provides robustness and high accuracy to estimate the SOC of Li-ion batteries. Over the past few years, the use of the AF algorithm has increased owing to its high accuracy and self-correcting nature against varying input signals (current).

H Infinity Filter $(\mathrm{H} \infty \mathrm{F})$

The $\mathrm{H}$ infinity Filter $(\mathrm{H} \infty \mathrm{F})$ is a popular methodology to solve the time-variant system like Li-ion battery [54]. $\mathrm{H} \infty \mathrm{F}$ is a simply designed and highly robust SOC estimation methodology. The method constructs a sub filter that can restrict the effects of uncertainty and perturbation of the system model. $\mathrm{H} \infty \mathrm{F}$ does not require any specification of the disturbances and model uncertainties, and it can also reduce the estimation error under the worst conditions; it is also known as a robust version of the Kalman filter [54]. The performance of $\mathrm{H} \omega \mathrm{F}$ is more sensitive to the design parameters. Zhang et al. [55] used the $\mathrm{H} \infty \mathrm{F}$ to address the issue of a battery SOC estimation in a $500 \mathrm{kV}$ transmission line inspection robot under unknown statistical properties and errors. Their proposed $\mathrm{H} \infty \mathrm{F}$ showed better result compared to the Kalman filter. In [56], a robust $\mathrm{H} \infty \mathrm{F}$ was presented to measure the SOC. Their proposed methodology considered the time varying parameters to model a Li-ion battery. The proposed algorithm was verified using six UDDS tests. The ME of their proposed algorithm was $2.49 \%$. Different variants of $\mathrm{H} \infty \mathrm{F}$ have also been reported [57-61]. The researchers mostly used the ECM battery model 
for SOC estimation. The HळF method formulates the linear matrix inequalities (LMIs), which lessen the effects of a NG system and disturbances. The recursive least square method and its variants has been employed to identify the parameters $[58,61]$. The $\mathrm{H} \infty \mathrm{F}$ has also been merged with some other methods to improve the SOC estimation accuracy [62-67]. This has been combined with neural networks [62], genetic algorithms (GAs) [63], and unscented Kalman filters (UKFs) [64,66]. The accuracy of all the joint estimators was high but the system was relatively complex. Table 5 lists the previous studies.

Table 5. MAE/ME of the $\mathrm{H} \infty \mathrm{F}$ and its variant-based method to estimate the SOC.

\begin{tabular}{lc}
\hline \multicolumn{1}{c}{ Reference } & MAE (\%) \\
\hline Zhang et al. 2012 [55] & Unspecified \\
Zhang et al. 2014 [56] & $\leq \pm 0.8436 \%$ \\
Zhu et al. 2017 [57] & $\leq \pm 3.96 \%$ \\
Zhang et al. 2017 [58] & $\leq \pm 0.02 \%$ \\
Xiong et al. 2017 [59] & $\leq \pm 1 \%$ \\
Xia et al. 2018 [60] & $\leq \pm 0.8 \%$ \\
Liu et al. 2018 [61] & $\leq \pm 0.6 \%$ \\
Alfi et al. 2014 [62] & ME $\leq \pm 1.1 \%$ \\
Lin et al. 2016 [63] & $\leq \pm 0.95 \%$ \\
Yu et al. 2017 [64] & $\leq \pm 0.5 \%$ \\
Lin et al. 2017 [66] & Unspecified \\
\hline
\end{tabular}

\section{Kalman Filter (KF)}

This is another method for the state estimation of a dynamic system. This method is most frequently used in the field of process control, surveying, transportation planning, biomedical field, and BMS design of EVs [68-70]. In recent years, in addition to its high computational complexity, the KF has attracted considerable interest to measure the SOC. The set of KF equations processes the measurements recursively [71]. The main feature of the KF is that it can filter out the disturbance (noise), high variations of measurements, and other inaccuracies of the system to estimate the states accurately. The KF tackles the uncertainty of the input values by taking the weighted average between the predicted and measured value [72]. To identify the system parameters, the KF can be used as a unit Jacobian transformation [68]. Urbain et al. [73] implemented the KF in real time to measure the SOC using simple ECM model. They showed that the maximum noted error was less than $5 \%$. The KF has also been merged with other SOC estimation techniques, such as the CC, OCV [72], GA [74], and back-propagation neural network [75]. Some variants of KF, such as the square root cubature KF (SRCKF) [76] and dual square root cubature KF (DSRCKF) [77] have been also reported. Table 6 lists the previous studies.

Table 6. MAE/ME of KF based SOC estimation method.

\begin{tabular}{lc}
\hline \multicolumn{1}{c}{ Reference } & MAE (\%) \\
\hline Urbain et al. 2007 [73] & ME $\leq \pm 5 \%$ \\
Yatsui et al. 2011 [72] & $\leq \pm 1.76 \%$ \\
Zhao et al. 2018 [75] & $\leq \pm 0.04 \%$ \\
Cui et al. 2018 [76] & $\leq \pm 0.71 \%$ \\
Chen et al. 2017 [77] & $\leq \pm 1.2 \%$ \\
\hline
\end{tabular}

\section{Extended Kalman Filter (EKF)}

Different variants of the KF, such as the extended Kalman filter (EKF), have been used to deal with nonlinearities of the system [54]. Recently, the EKF has attracted substantial interest as a method to measure the SOC [78]. In the EKF, nonlinear system dynamics and model measurements have been expanded through a linearization method, which linearize the battery model at each time step. The state space model compares the predicted and measured value to increase the SOC estimation accuracy 
of a Li-ion battery [68]. The OCV-SOC estimator were designed using the EKF [79-82]. The EChM was also adopted [79]. The adaptive extended Kalman filter (AEKF) scheme was implemented on the ECM for SOC estimation [80,81]. The results highlighted the robustness and high accuracy of the proposed techniques. In the Thevenin ECM, an extra RC branch was added to improve the estimation accuracy using the EKF [83-85]. The hysteresis, Coulomb efficiency and polarization characteristics of Li-ion battery were also analyzed [83,86]. Mastali et al. [87] implemented the EKF and dual EKF to predict the SOC. They also discussed the battery geometry effects on the battery parameters. Some variants of the EKF have also been reported [88-90]. The robust EKF (REKF) addresses the uncertainty in the battery modelling and linearization error. The model also provides robustness against system noise. Xiong et al. [91] proposed a dual time scale EKF SOC estimator. They used a macro scale for battery parameter identification and a micro scale for the SOC prediction. Similarly, another study [92] used the temperature compensated model with the EKF to address the effects of temperature on the battery parameters. A grey predicted EKF was proposed to eliminate the effects of the truncation error [93]. The EKF in conjunction with a stochastic fuzzy neural network (SFNN) has been utilized for SOC estimation [94]. The SFNN modeled the nonlinear dynamic characteristics of the battery and the EKF estimated the SOC of a Li-ion battery. Table 7 lists the comparison of the previous studies.

Table 7. MAE/ME of the EKF, variants of the EKF and hybrid EKF-based SOC estimation method.

\begin{tabular}{lc}
\hline \multicolumn{1}{c}{ Reference } & MAE (\%) \\
\hline He et al. 2011 [83] & $\leq \pm 1.06 \%$ \\
Zhu et al. 2012 [84] & $\mathrm{ME} \leq \pm 4.2 \%$ \\
Xiong et al. 2012 [81] & $\leq \pm 2.0 \%$ \\
Jiang et al. 2013 [82] & $\leq \pm 1.0 \%$ \\
Hu et al. 2013 [88] & $\leq \pm 1.0 \%$ \\
Chen et al. 2013 [85] & $\leq \pm 3.0 \%$ \\
Xiong et al. 2014 [91] & $\leq \pm 1.5 \%$ \\
Sepasi et al. 2014 [89] & $\leq \pm 1.5 \%$ \\
Wang et al. 2017 [90] & Unspecified \\
Xie et al. 2018 [86] & $\mathrm{ME} \leq \pm 2.0 \%$ \\
Yang et al. 2017 [92] & $\mathrm{ME} \leq \pm 3.0 \%$ \\
Pan et al. 2017 [93] & $\leq \pm 1.3 \%$ \\
Huang et al. 2018 [78] & $\mathrm{Unspecified}$ \\
Xu et al. 2012 [94] & $\mathrm{ME} \leq \pm 0.6 \%$ \\
\hline
\end{tabular}

\section{Unscented Kalman Filter (UKF)}

When a system, such as a Li-ion battery, has severe non-linearities, tuning of the EKF becomes arduous and it provides uncertain estimates because the EKF depends mainly on linearization to disseminate the mean and covariance of the state [54]. Therefore, an UKF is used to minimize the linearization error of EKF. The basic concept of the UKF is that it is simpler to assess a probability distribution than a random non-linear function [68]. A deterministic "sigma point filter" approach is used to obtain the covariance and mean of the state with minimum sample points. The UKF carefully calculates the selected perturbations about the current state. The perturbed state propagates to calculate the samples for the estimated state and predicted measurement. In the UKF, there is no need to calculate the Jacobian matrix. The correctness of the UKF is better than EKF because it can predict the high order non-linear system states accurately. The UKF is more complex than EKF because of the modeling uncertainties and perturbations.

The UKF was implemented in several studies for the SOC estimation of the batteries [95-99]. The CC and simple model was considered with the UKF for a SOC estimation [95]. Tian et al. [96] used the UKF with a modified ECM to study the effects different temperatures and charge rates. Some variants of the UKF have also been reported [100-107]. In [100,102], an adaptive UKF (AUKF) adaptively adjusts the perturbation covariance of the state's value; the zero-state battery hysteresis model was selected to reduce the complexity [100]. A machine learning algorithm was used to train the battery 
model [101]. The comparison showed that the AUKF has a better accuracy and convergence rate than the EKF, AEKF, and UKF. Cai et al. [103] addressed the issue of the battery model accuracy. They proposed a fractional variable order model, which updates the value of the battery model adaptively. The UKF was implemented to estimate the SOC for a fractional system. Another variant of UKF method was used to calculate the noise directly [104]. This algorithm ensures symmetry in the matrices. The particle filter (PF) was also combined with the UKF to increase its robustness [108]. The PF helps to decrease the convergence time at the start because of the high initial error. Table 8 lists the performance of the UKF and its variants.

Table 8. MAE/ME of the UKF, variants of the UKF and hybrid UK-based SOC estimation method.

\begin{tabular}{lc}
\hline \multicolumn{1}{c}{ Reference } & MAE (\%) \\
\hline He et al. 2013 [95] & ME $\leq \pm 4 \%$ \\
Tian et al. 2014 [96] & $\leq \pm 1.25 \%$ \\
Wang et al. 2018 [97] & Unspecified \\
Sun et al. 2011 [100] & $\leq \pm 1.0 \%$ \\
Du et al. 2014 [101] & $\leq \pm 1.5 \%$ \\
Partovibakhsh et al. 2015 [102] & $\leq \pm 0.028 \%$ \\
Cai et al. 2017 [103] & ME $\leq \pm 1.51 \%$ \\
Liu et al. 2017 [104] & $\leq \pm 0.5 \%$ \\
Peng et al. 2017 [105] & $\leq \pm 1.49 \%$ \\
Chen et al. 2017 [106] & $\leq \pm 2.88 \%$ \\
Li et al. 2018 [107] & $\leq \pm 1.5 \%$ \\
Li et al. 2018 [108] & $\leq \pm 0.31 \%$ \\
\hline
\end{tabular}

Sigma Point Kalman Filter (SPKF)

This method is another way to improve the efficiency and correctness of a SOC measurement of a nonlinear dynamic state space model, such as a Li-ion battery. The SPKF calculates the statistics of arbitrary variables that experience a nonlinear transformation, and then forms the Kalman time and measurement equations, which are the Gaussian assumption-based Bayesian estimation equations [109]. The variance of the error in the posterior covariance was considered to compensate for the linearization error. The posterior covariance and mean were calculated for limited values [16]. In the SPKF, there is no need to calculate the analytical derivatives (Jacobians and Hessians), as in the case of EKF. The SPKF depends only on a functional evaluation. The SPKF has better accuracy and robustness with same complexity as the EKF $[71,109,110]$.

Plett [71] implemented the SPKF and EKF for SOC measurement. The results showed that the SPKF has high accuracy than the EKF. In his subsequent work, Plett [110] introduced a variant of the SPKF to increase its robustness. The UDDS test was performed to check the robustness of the proposed SOC estimation strategy for a Li-ion battery. The joint estimation of the inner resistance and SOC of a Li-ion battery by keeping other parameters constant was also proposed [111]. Another study compared the Luenberger observer, EKF and SPKF [112]. Another variant is strong tacking sigma point Kalman filter (STSPKF) [113], which used a strong tacking factor to adjust the process and measure the perturbation in real time. Table 9 summarizes the performance of the SPKF and its variants.

Table 9. MAE/ME of the SPKF and variants of the SPKF-based SOC estimation method.

\begin{tabular}{lc}
\hline \multicolumn{1}{c}{ Reference } & MAE (\%) \\
\hline Plett. 2006 [71] & ME $\leq \pm 0.9 \%$ \\
He et al. 2012 [111] & Unspecified \\
Li et al. 2013 [112] & Unspecified \\
Li et al. 2015 [113] & $\leq \pm 0.83 \%$ \\
\hline
\end{tabular}




\section{Particle Filter (PF)}

In the particle filter (PF), a Monte Carlo approximation approach is used to make a state estimation [54]. In the PF, some random large particles have been chosen to approximate the conditional probability density function [68]. This method has higher efficiency but at the cost of more complexity. Different researchers used the PF to SOC estimation [114-117]. The PF was merged with other techniques to improve its efficiency [118-120]. Fuzzy rules were used to model the battery and the PF was utilized to provide a co-estimation of the state of maximum power available (SoMPA) and SOC [118]. Furthermore, the forgetting factor RLS method was also used to determine the battery parameters with the PF as a SOC estimator [120]. Different variants of the PF have also been reported [121,122]. Recently, Ye et al. [123] proposed an online double scale and adaptive particle filter. They reduced the computational cost of the algorithm by considering that the battery parameters change more slowly than the SOC. They showed that the MAE of SOC estimation is less than 1\% after the systems stability, and the convergence time of the proposed algorithm was only 136 second. Table 10 lists the performance of the UKF and its variants.

Table 10. MAE/ME of the PF, variants of the PF and hybrid PF-based SOC estimation method.

\begin{tabular}{lc}
\hline \multicolumn{1}{c}{ Reference } & MAE (\%) \\
\hline Gao et al. 2011 [114] & Unspecified \\
Schwunk et al. 2013 [115] & Unspecified \\
He et al. 2013 [117] & $\leq \pm 3.5 \%$ \\
Burgos-Mellado et al. 2016 [118] & Unspecified \\
Zhou et al. 2016 [119] & ME $\leq \pm 1.61 \%$ \\
Xia et al. 2017 [121] & $\leq \pm 0.5 \%$ \\
Li et al. 2018 [122] & $\leq \pm 1 \%$ \\
Du et al. 2018 [120] & ME $\leq \pm 3.5 \%$ \\
Ye et al. 2018 [123] & $\leq \pm 1 \%$ \\
\hline
\end{tabular}

Recursive Least Square (RLS)

This is a very useful method to identify the parameters of a time-varying system. The least square (LS) method identifies the system parameters by minimizing the least square error between the measured and estimated value [68]. The RLS is utilized in AF to determine the gain; it makes this process recursive and estimates the parameters of the system by amalgamating new information at each time step.

The RLS and its variants have been used widely to determine the parameters of Li-ion battery model [124-133]. The RLS has been applied to identify the characteristic of the battery for a $1^{\text {st }}$ order ECM $[124,129,132]$. The OCV estimator was designed to determine the SOC. The results highlighted the robustness and high accuracy of the RLS. A recurrent neural network and RLS with a time dependent forgetting factor was utilized to SOC estimation [125]. The fading KF (FKF) was also implemented for SOC estimation [126]. The exponential and variable forgetting factor RLS methods were also used to estimate the SOC $[127,128,130]$. Table 11 lists the performance of the RLS SOC estimation method.

Table 11. MAE/ME of the RLS, variants of the RLS and hybrid RLS-based SOC estimation method.

\begin{tabular}{lc}
\hline \multicolumn{1}{c}{ Reference } & MAE (\%) \\
\hline Hu et al. 2011 [124] & ME $\leq \pm 2.12 \%$ \\
Eddahech et al. 2012 [125] & $\leq \pm 1.03 \%$ \\
Safwat et al. 2017 [128] & $\leq \pm 3 \%$ \\
Duong et al. 2017 [129] & $\leq \pm 1.8 \%$ \\
Xia et al. 2017 [130] & $\leq \pm 1.41 \%$ \\
Ali et al. 2018 [132] & $\leq \pm 1.93 \%$ \\
Zhang et al. 2018 [133] & $\leq \pm 1 \%$ \\
\hline
\end{tabular}




\subsubsection{Observer-Based estimation (OBE)}

Non-Linear Observer (NLO)

Recently, the linear observer (LO) and NLO has been utilized for state estimation of batteries. The main drawback of the LO is the high estimation error compared to the NLO [134]. Xie et al. [135] introduced the NLO SOC estimator methodology. Their proposed methodology did not use a complex matrix operation for the estimation. The SOC was estimated using the OCV state space equations. The proposed methodology showed less complexity, higher precision, and better robustness than the EKF and sliding mode observer. An optimal adaptive gain nonlinear observer (OAGNO) was proposed in another study to state estimation of a battery [136]. Recently, the particle-swarm optimization algorithm was used to tune the observer. which showed high accuracy and robustness [137]. Other variants of NLO were also proposed for the improvement of estimation accuracy of SOC of a Li-ion battery $[138,139]$. For comparison of NLO-based SOC estimation methods, see Table 12.

Table 12. MAE/ME of the NLO-based SOC estimation method.

\begin{tabular}{lc}
\hline \multicolumn{1}{c}{ Reference } & MAE (\%) \\
\hline Xia et al. 2014 [135] & ME $\leq \pm 2.89 \%$ \\
Tian et al. 2017 [136] & $\leq \pm 0.74 \%$ \\
Ma et al. 2017 [137] & $\leq \pm 2.0 \%$ \\
Li et al. 2017 [138] & $\leq \pm 0.35 \%$ \\
Chen et al. 2018 [139] & $\mathrm{ME} \leq \pm 2.98 \%$ \\
\hline
\end{tabular}

\section{Sliding Mode Observer (SMO)}

This method enhances the control, robustness, and stability of a Li-ion battery system against perturbation [140-145]. The state equations are used to establish a battery model, and these equations are used for the observer. Feedback is taken to control the sliding regtime to ensure robustness. The SMO can compensate for modelling errors. Du et al. [146] proposed an adaptive SMO to address the effect of chattering to during state estimation of a battery.

The 2nd order ECM was selected to compare the conventional and proposed SMO. The proposed SMO showed better accuracy with a high convergence rate. The chattering effect was also addressed using a second-order discrete-time SMO [147]. In [148], the dual SMO was proposed considering the capacity fading effect for SOC estimation. To improve the efficiency, accuracy, and robustness of the SMO, some variants, such as the adaptive gain SMO (AGSMO) [149], adaptive switching gain SMO (ASGSMO) [150], super-twisting SMO (STSMO) [151], fractional order SMO (FOSMO) [152], and Fuzzy SMO (FSMO) [153], have been reported in the literature. Table 13 shows the comparison of the SMO-based SOC estimation methods.

Table 13. MAE/ME of the SMO-based SOC estimation method.

\begin{tabular}{lc}
\hline \multicolumn{1}{c}{ Reference } & MAE (\%) \\
\hline Kim et al. 2008 [140] & ME $\leq \pm 3 \%$ \\
Ning et al. 2016 [143] & ME $\leq \pm 2 \%$ \\
Ma et al. 2016 [144] & ME $\leq \pm 3 \%$ \\
Xia et al. 2017 [145] & $\leq \pm 0.86 \%$ \\
Chen et al. 2013 [150] & Unspecified \\
Zhong et al. 2017 [153] & $\leq \pm 1 \%$ \\
Huangfu et al. 2018 [151] & $\leq \pm 2 \%$ \\
Chen et al. 2018 [148] & $\leq \pm 1 \%$ \\
\hline
\end{tabular}


Proportional Integral Observer (PIO)

The proportional integral observer (PIO) is a widely adopted, simple, and efficient method, because the feedback control system can be replaced easily using PIO. Xu et al. [154] adopted the 1st order ECM for SOC estimation of a battery through the use of a PIO. The UDDS cycle was used for validation. The robustness of their proposed methodology was quite high with acceptable accuracy. In their subsequent work, $\mathrm{Xu}$ et al. [155] jointly used the CC and model-based estimation method to improve the efficiency. They utilized a GA and PIO to determine the parameters and the SOC of a battery, respectively. The highpoint of their second work was that it could work easily without laboratory testing data. A comparison of the KF, SMO, Luenberger observer, and PIO was done in $[156,157]$. The results highlighted the superior performance of the PIO. The PIO is also used in combination with drifting corrector to address the issues of a flat OCV-SOC relation and current sensor error for a $\mathrm{LiFePO}_{4}$ battery [26]. The issue of sensor error was addressed by dividing the measured current into a true value, current sensor drifting, and zero-mean noise of the sensor. Zheng et al. [158] merged the PIO and CC to estimate the SOC, capacity, and resistance of EChM. The influence of aging on the estimation was also addressed. Recently [159], the PIO was employed to enhance the linearization performance of the EKF. The RLS method was used to identify the 1st order ECM. The proposed methods show good robustness with a dynamic current at different temperatures. Also in another study [160], the two PIO were used to compensate for the inaccuracy of the SOC and current sensor error. Furthermore, they compared their proposed method with the EKF. They showed that their proposed method showed less complexity and higher accuracy than the EKF. For further comparison of the PIO-based SOC estimation methods, see Table 14.

Table 14. MAE/ME of the PIO-based SOC estimation method.

\begin{tabular}{lc}
\hline \multicolumn{1}{c}{ Reference } & MAE (\%) \\
\hline Xu et al. 2014 [154,155] & $\mathrm{ME} \leq \pm 2 \%$ \\
Tang et al. 2015 [26] & $\mathrm{ME} \leq \pm 2.5 \%$ \\
Zheng et al. 2016 [158] & $\mathrm{ME} \leq \pm 3.58 \%$ \\
Wei et al. 2017 [159] & $\mathrm{ME} \leq \pm 5 \%$ \\
Meng et al. 2018 [160] & $\mathrm{ME} \leq \pm 1.86 \%$ \\
\hline
\end{tabular}

Luenberger Observer (LO)

The Luenberger observer (LO) has been also used to provide state estimations of non-linear and time varying systems $[157,161]$. Hu et al. [162] applied the LO for SOC estimation. They used a 1st order ECM for the estimation; the nonlinear least square method was utilized to identify the battery parameters and a stochastic gradient approach was used to set the observer gain. The proposed observer had low computational complexity. LO-based SOC estimator for EChM was also proposed by including the effects of variable temperature to improve the SOC estimation accuracy for Li-ion battery [163]. Recently, Tang et al. [164] presented another variant of the LO, a multi-gain Luenberger observer (MGLO). They showed that the proposed observer addressed the issues of modeling inaccuracy and sensor error for the SOC estimation. Their proposed method has higher robustness, better accuracy, and similar complexity to the LO. Table 15 provides the comparison of the LO-based SOC estimation methods.

Table 15. MAE/ME of the LO-based SOC estimation method.

\begin{tabular}{lc}
\hline \multicolumn{1}{c}{ Reference } & MAE (\%) \\
\hline Hu et al. 2010 [162] & ME $\leq \pm 2.5 \%$ \\
Tanim et al. 2015 [163] & ME $\leq \pm 2.6 \%$ \\
Tang et al. 2017 [164] & Unspecified \\
\hline
\end{tabular}




\subsection{Computer Intelligence-Based Estimation Methods}

\subsubsection{Genetic Algorithm (GA)}

The genetic algorithm (GA) is a biologically inspired optimization method to find the unknown model parameters of a nonlinear system, such as a Li-ion battery. The GA generates a string of chromosomes randomly and uses biological operators, such as crossover, selection, and mutation, mutation, to find the optimal values. Zheng et al. [165] used the voltage-capacity rate curve and implemented a GA to model the battery pack. They used four cell series-connected Li-ion batteries and determined the capacities of the entire pack and individual cells. The maximum average SOC error of a cell in a string was $0.54 \%$. The GA was also implemented to find the second order ECM parameters of a battery [166]. The formula using identified diffusion capacitance was derived to determine the $\mathrm{SOH}$ of a Li-ion battery. The GA fused with some other model-based estimation methods was used to estimate the SOC $[155,167-171]$. The GA was also utilized in tuning of the fading KF to further improve the estimation of the SOC for a Li-ion battery [126]. Recently, the 3D OCV-SOC method was proposed in which GA was utilized to find the SOC and SOH of a battery with high accuracy and good convergence rate [172]. Table 16 reports the MAE for the GA and its variants.

Table 16. MAE/ME of the GA, variants of the GA and hybrid GA-based SOC estimation method.

\begin{tabular}{lc}
\hline \multicolumn{1}{c}{ Reference } & MAE (\%) \\
\hline Zheng et al. 2013 [165] & $\leq \pm 0.55 \%$ \\
Xu et al. 2014 [155] & $\leq \pm 2.0 \%$ \\
Khan et al. 2014 [168] & ME $\leq \pm 5.0 \%$ \\
Lim et al. 2016 [126] & $M E \leq \pm 2.0 \%$ (in UDDS) $\leq \pm \pm 3.0 \%$ (in real driving EV) \\
Mu et al. 2017 [171] & $\leq \pm 2.98 \%$ \\
Yang et al. 2017 [172] & ME $\leq \pm 2.1 \%$ \\
Chen et al. 2018 [169] & $\leq \pm 1.0 \%$ \\
\hline
\end{tabular}

\subsubsection{Bacterial Foraging Algorithm (BFA)}

The bacterial foraging algorithm (BFA) is a nature-inspired optimization technique that is established on the social foraging behavior of Escherichia coli bacteria. The BFA has been successfully used to solve many engineering and mathematical problems because of its simplicity and high efficiency $[173,174]$. The BFA was also used to estimate the unknown parameters of the single particle EChM of a Li-ion battery [175].

\subsubsection{Particle Swarm Optimization (PSO)}

PSO is also a nature-inspired approach. The basic idea of this methodology is stimulated from the social behavior of different species, such as birds or fishes, interacting with each other or with the surroundings [176]. In this methodology, the main objective is information sharing in the group, where every individual bird in the flock does not know the precise location of the food, but they can track down the food site easily through information sharing [177]. PSO has been implemented successfully in many engineering problems to find optimal solutions [174,177-179]. PSO has been used to identify the model parameters of a Li-ion battery [180-186]. Recently, an improved EKF SOC estimator has been proposed in which PSO was utilized to identify the time varying parameters of the Li-ion battery [187]. Their proposed estimator produced a better result compared to the traditional EKF. Table 17 compares the MAE for PSO and its variants. 
Table 17. MAE/ME of the PSO, variants of the PSO and hybrid PSO-based SOC estimation method.

\begin{tabular}{lc}
\hline \multicolumn{1}{c}{ Reference } & MAE (\%) \\
\hline Sheikhan et al. 2012 [178] & $\leq \pm 1.9 \%$ \\
Aung et al. 2015 [185] & ME $\leq \pm 3.35 \%$ \\
Yu et al. 2017 [183] & Unspecified \\
Ye et al. 2017 [186] & ME $\leq \pm 1.0 \%$ \\
Lai et al. 2018 [187] & ME $\leq \pm 1.0 \%$ \\
\hline
\end{tabular}

\subsubsection{Fuzzy Logic (FL)}

FL is another method to identify the unknown parameters of a highly complex and nonlinear system, such as a Li-ion battery. FL does not require a precise mathematical model of the system, as it only uses the input data and identifies the parameters using the fuzzy rule base. The working principle of FL can be divided easily into the following stages: fuzzification, fuzzy rule base, inference engine, and defuzzification [3]. FL requires however high storage and computational time to determine the parameters of a complex and nonlinear system. FL was also used to estimate the parameters of the SOC with improved accuracy [188-190]. Furthermore, the use of FL fused with other SOC estimation techniques has also been reported [118,191-193]. Li et al. [194] used RLS with a fuzzy adaptive forgetting factor to identify the time-varying parameters of a Li-ion battery; the adaptive UKF was used to estimate the SOC of the Li-ion battery [194]. For further comparison, see Table 18.

Table 18. MAE/ME of the FL-based SOC estimation method.

\begin{tabular}{lc}
\hline \multicolumn{1}{c}{ Reference } & MAE (\%) \\
\hline Salkind et al. 1999 [188] & ME $\leq \pm 5.0 \%$ \\
Singh et al. 2006 [189] & Unspecified \\
Malkhandi 2006 [190] & ME $\leq \pm 5.0 \%$ \\
Li et al. 2016 [194] & $\leq \pm 0.59 \%$ \\
\hline
\end{tabular}

\subsubsection{Neural Network (NN)}

The neural network $(\mathrm{NN})$ is a computing system that is basically inspired by the human brain. The NN is a framework of many different machine learning algorithms to perform different tasks [195]. The NN has self-adaptability and learning abilities to establish a highly complicated and non-linear system, such as a Li-ion battery. The basic NN uses a three-layer formation, and input and output layer-containing neurons with system specifications. The relationship between the I/O layer is developed through neurons and hidden layers. The measurements of electric charge and the internal impedance were considered to form an NN [196,197]. The fused NN and EKF were applied to predict the SOC of a battery $[198,199]$. The NN was trained offline using the battery charge/discharge data [198]. The feed forward NN (FFNN) was introduced to SOC estimation [199]. The parameters of the battery were the inputs, and the UKF was used to decrease the prediction error. Dong et al. [200] proposed a wavelet NN-based battery model. They also considered temperature and current to further improve the modeling accuracy. Then, PF was employed to find the SOC. Another study compared the open and closed loop NN SOC estimators, in which they showed that the closed-loop NN estimator gives better performance than open loop NN [201]. Furthermore, the dual SOC and state of energy (SOE) estimator can be constructed using a NN [202]. Some variants of the NN were also used to SOC estimation [203-209]. Recently, Cui et al. [210] combined the discrete wavelet transform and wavelet NN methods to estimate the SOC. The wavelet NN was trained using the Levenberg Marquardt (L-M) technique. The inputs of the wavelet NN were managed by a discrete wavelet decomposition and reconstitution. Their proposed methodology produced better results than the BPNN, FFNN, L-M based BPNN, discrete wavelet transforms back propagation NN, and EKF. The backtracking search 
algorithm (BSA) can be used to improve the performance of BPNN [211]. The comparison of MAE for NN-based SOC estimation methods is shown in Table 19.

Table 19. MAE/ME of the NN-based SOC estimation method.

\begin{tabular}{lc}
\hline \multicolumn{1}{c}{ Reference } & MAE (\%) \\
\hline Affanni et al. 2003 [196] & $\mathrm{ME} \leq \pm 4.6 \%$ \\
Rui-hao et al. 2011 [197] & $\mathrm{ME} \leq \pm 4.91 \%$ \\
Chen et al. 2011 [212] & $\leq \pm 1.0 \%$ \\
He et al. 2014 [199] & $\mathrm{ME} \leq \pm 2.5 \%$ \\
Dong et al. 2015 [200] & $\mathrm{ME} \leq \pm 4.0 \%$ \\
Wang et al. 2016 [202] & $\mathrm{ME} \leq \pm 2.5 \%$ \\
Hussein 2015 [203] & $\leq \pm 0.03 \%$ \\
Tong et al. 2016 [204] & $\leq \pm 3.8 \%$ \\
Dang et al. 2016 [205] & $\leq \pm 0.75 \%$ \\
Shi et al. 2010 [207] & $\leq \pm 1.25 \%$ \\
Kang et al. 2014 [208] & $\leq \pm 3.0 \%$ \\
Cui et al. 2018 [210] & $\leq \pm 0.93 \%$ \\
Hannan et al. 2018 [211] & $\leq \pm 0.87 \%$ \\
\hline
\end{tabular}

\subsubsection{Adaptive Neuro Fuzzy Inference System (ANFIS)}

An ANFIS is an advanced form of the artificial NN, which is based mainly on the Takagi-Sugeno fuzzy inference system. The ANFIS has the benefits of FL and NN in a single framework. ANFIS is an extraordinary tool for modeling, optimization, and nonlinear mapping. Shen et al. [213] implemented the ANFIS-based SOC estimator using different discharge current profiles to validate the proposed technique. Five inputs and one output ANFIS model were also presented in [214]. The inputs were selected using linear correlation analysis, partial correlation analysis, and nonparametric correlation analysis. A gradient and least square algorithm were used to train the ANFIS. The comparison showed the better performance of ANFIS over BPNN. In another study [215], capacity and temperature distributions were taken into account to estimate the SOC. The experiments with different battery discharging current were carried out to validate their proposed technique. Furthermore, the performance of CC and ANFIS based Li-ion battery SOC estimator were also compared in [216]. Table 20 shows the studies using ANFIS method and their MAE.

Table 20. MAE/ME of the ANFIS-based SOC estimation method.

\begin{tabular}{lc}
\hline \multicolumn{1}{c}{ Reference } & MAE (\%) \\
\hline Shen et al. 2002 [213] & $\leq \pm 0.92 \%$ \\
Cai et al. 2003 [214] & ME $\leq \pm 4.44 \%$ \\
Chau et al. 2004 [215] & $\leq \pm 1.0 \%$ \\
Fotouhi et al. 2015 [216] & $\leq \pm 2.0 \%$ \\
Dai et al. 2015 [217] & Unspecified \\
Awadallah and Venkatesh 2016 [218] & Unspecified \\
\hline
\end{tabular}

\subsubsection{Support Vector Machine (SVM)}

In recent years, support vector machine (SVM) techniques have attracted considerable attention. The SVM is becoming a powerful tool to solve regression problems in nonlinear systems. The SVM uses different kernel functions and regression algorithms to transmute a nonlinear model into a linear model. On the other hand, the complexity of the SVM system is very high due to the complex quadratic programming. The voltage, current and temperature were considered to SOC estimation using the SVM [219-221]. The least square algorithm was used to improve the efficiency of the SVM [219]. Similar inputs were used to establish a relationship with the SOC using the weighted least squares SVM. A study used [222] extended Huber residual estimation algorithm in the objective function to achieve better robustness than the conventional SVM. Hu et al. [223] used a double step search to select 
the parameters of support vector regression using a radial basis kernel function. Their proposed SVM showed better results compared to the NN. Another study [224] addressed the issue of sensor noise to reduce the errors. Their proposed strategy showed better results than the conventional SVM. Table 21 shows the study on the SVM-based SOC estimation method.

Table 21. MAE/ME of the SVM-based SOC estimation method.

\begin{tabular}{lc}
\hline \multicolumn{1}{c}{ Reference } & MAE (\%) \\
\hline Chen et al. 2011 [222] & $\leq \pm 1.09 \%$ \\
Wu et al. 2011 [219] & $M E \leq \pm 5.0 \%$ \\
Anton et al. 2013 [221] & $M E \leq \pm 6.0 \%$ \\
Sheng et al. 2015 [224] & $\leq \pm 0.30 \%$ \\
\hline
\end{tabular}

\subsubsection{Multivariate Adaptive Regression Splines (MARS)}

Friedman [225] introduced a new type of flexible regression analysis for high dimensional data called multivariate adaptive regression splines (MARS). The MARS model is an extension of product-spline-basis functions, where the parameters and basis function can be calculated automatically using the data. The main idea of MARS method is inspired basically by the recursive partitioning approach. The main advantage of the MARS method over the recursive partitioning approach is that it can generate continuous models using continuous derivatives. Antón et al. [226] used the MARS technique to SOC estimation. The parameters of the battery were used to extract the battery parameters, basis function, and coefficients. The model was evaluated with a determination coefficient of 0.98 , and an accuracy of $1 \%$ was accomplished during the SOC level between $25 \%$ to $90 \%$. The main advantage of their proposed technique is that it can be implemented easily on a low-cost microcontroller. In their subsequent work [227], a hybrid PSO optimized MARS technique to SOC estimation was proposed. They used a PSO algorithm to identify the optimal parameters of the MARS model, which further reduces the training time of the MARS model.

\section{Discussion}

The Li-ion battery is a highly complex electrochemical system and its performance degraded by different factors, such as hysteresis, aging and operating conditions. Therefore, it is very challenging task to estimate the SOC of a Li-ion battery accurately. Several discussed SOC estimation methods from easier to complicated are under investigation. The $\mathrm{OCV}$ method has a relatively high accuracy to estimate the SOC of Li-ion battery. The main shortcoming of the OCV method is its long relaxing time to reach equilibrium state to measure terminal voltage as OCV. So, the OCV method cannot be directly used to estimate the SOC of Li-ion battery in an EV application. The IR method use battery resistance to measure SOC, the main lapse is the low resistance value for wide SOC range. The CC method showed reliable results when the initial SOC of the Li-ion battery is known. The accuracy of the CC method mainly depends upon the initial SOC value and resolution of the sensor. The CC method fused with other methods like OCV and model-based is a good option to estimate the SOC in EVs. The accuracy of MB estimation methods mainly depends upon model exactness. So, battery models should guarantee not only to capture the complex chemical reaction of Li-ion battery, but they also consider the effects of capacity degradation, climate changes, and mechanical stress. Now a days, the KF family based SOC estimator is the most popular in online estimation applications. The advantages and limitation of KF and its variants-based methods has been listed in Table 22. The accuracy of the machine learning method is very high but it needs high training time and data storage size. The computational cost of these methods is also high. Table 22 summarizes the merits and limitations of each SOC estimation method discussed above. 
Table 22. Summary of the classified SOC estimation methods for Li-ion batteries.

\begin{tabular}{|c|c|c|c|}
\hline Method & Advantages & Limitations & Applicability in EVs \\
\hline $\mathrm{OCV}$ & $\begin{array}{l}\text { It is simple and easily implementable, and it } \\
\text { has high accuracy. }\end{array}$ & $\begin{array}{l}\text { This technique cannot be implemented for online estimations because it } \\
\text { requires a long resting time to reach equilibrium, and precise measurements of } \\
\text { the OCV are difficult due to the flat region in the middle of the OCV-SOC curve. } \\
\text { Therefore, this method is only suitable to train and calibrate other methods. }\end{array}$ & No \\
\hline EMF & This method is simple and inexpensive. & $\begin{array}{l}\text { This technique requires significant time to model OCV relaxation after } \\
\text { current disruption. }\end{array}$ & No \\
\hline IR & It is simple and easily implementable. & $\begin{array}{l}\text { It has low accuracy because large variations of the SOC have low impact on } \\
\text { the change in resistance. Therefore, it is difficult to measure a small } \\
\text { resistance. }\end{array}$ & No \\
\hline IS & $\begin{array}{l}\text { This method can measure the SOC online with } \\
\text { reasonable accuracy. }\end{array}$ & $\begin{array}{l}\text { This technique only has good results for identical charging and discharging } \\
\text { currents. Therefore, it is unsuitable for EVs because of the large variations in } \\
\text { charge/discharge current. It also has an effect on battery aging and } \\
\text { temperature. }\end{array}$ & No \\
\hline $\mathrm{CC}$ & $\begin{array}{l}\text { It is simple and easily implementable with low } \\
\text { computation cost. }\end{array}$ & $\begin{array}{l}\text { Several factors, such as an unknown initial SOC, aging, temperature, } \\
\text { self-discharging, coulomb efficiency and device precision, affect its accuracy. }\end{array}$ & Yes \\
\hline $\mathrm{H} \infty \mathrm{F}$ & $\begin{array}{l}\text { This method has reasonable accuracy, less } \\
\text { computational cost, and good convergence } \\
\text { rate. }\end{array}$ & $\begin{array}{l}\text { The accuracy of the model can be affected by the aging, hysteresis and } \\
\text { operating conditions (temperature) of the Li-ion battery. }\end{array}$ & Yes \\
\hline KF & $\begin{array}{l}\text { This method can estimate the states affected } \\
\text { by external perturbations in real time and with } \\
\text { high accuracy. }\end{array}$ & $\begin{array}{l}\text { This method cannot be applied directly to estimate the states of a non-linear } \\
\text { system. It depends strongly on the correctness of the model and measuring } \\
\text { device precision, and the complexity of this technique is very high. }\end{array}$ & Yes \\
\hline EKF & $\begin{array}{l}\text { It can predict the states of a system accurately } \\
\text { under noisy and inaccurate initial conditions. }\end{array}$ & $\begin{array}{l}\text { The accuracy of this method depends mainly on the linearization. The } \\
\text { linearization error could be significant for a highly nonlinear system. It also } \\
\text { has low robustness. }\end{array}$ & Yes \\
\hline UKF & $\begin{array}{l}\text { This method can easily estimate states of any } \\
\text { higher order (3rd order) nonlinear system. } \\
\text { Unlike the EKF, it does not require to compute } \\
\text { the Jacobian matrix and Gaussian noise. }\end{array}$ & $\begin{array}{l}\text { Like the EKF, it has low robustness due to vagueness in modelling and } \\
\text { perturbation. }\end{array}$ & Yes \\
\hline SPKF & $\begin{array}{l}\text { It has high accuracy and does not require to } \\
\text { compute the Jacobian matrix. }\end{array}$ & It is complicated and requires lengthy calculations to estimate the SOC. & Yes \\
\hline $\mathrm{PF}$ & $\begin{array}{l}\text { This method has high accuracy, less } \\
\text { computation cost, and good convergence rate. }\end{array}$ & It requires a very powerful mathematical tool to solve it. & Yes \\
\hline
\end{tabular}


Table 22. Cont.

\begin{tabular}{|c|c|c|c|}
\hline Method & Advantages & Limitations & Applicability in EVs \\
\hline RLS & $\begin{array}{l}\text { This method has high accuracy and can } \\
\text { eradicate the noise of the measured voltage. }\end{array}$ & $\begin{array}{l}\text { The system and noise should satisfy the Gaussian distribution for better } \\
\text { accuracy. It has high complexity and computational cost. Its accuracy } \\
\text { mainly depends on the correctness of the battery model and selection of the } \\
\text { forgetting factor. }\end{array}$ & Yes \\
\hline NLO & $\begin{array}{l}\text { This method has good convergence speed, } \\
\text { reasonable computation cost, and high } \\
\text { accuracy. }\end{array}$ & It is hard to determine a suitable gain for high accuracy. & Yes \\
\hline $\mathrm{SMO}$ & $\begin{array}{l}\text { This method enhances the tracking control to } \\
\text { ensure stability and robustness. }\end{array}$ & $\begin{array}{l}\text { It is hard to determine a suitable switching gain to control the sliding } \\
\text { regtime for high accuracy. }\end{array}$ & Yes \\
\hline $\mathrm{PIO}$ & $\begin{array}{l}\text { It can estimate the SOC accurately in the } \\
\text { presence of an unknown initial SOC, imprecise } \\
\text { battery capacity, and noisy current sensor. }\end{array}$ & The controller design has a significant effect on the estimation accuracy. & Yes \\
\hline $\mathrm{LO}$ & $\begin{array}{l}\text { This method is accurate and robust in the } \\
\text { presence of modeling and sensor inaccuracy. }\end{array}$ & The selection of appropriate gain for the observer is a difficult task. & Yes \\
\hline GA & $\begin{array}{l}\text { This method has high accuracy and is robust } \\
\text { in the presence of noisy environment. }\end{array}$ & $\begin{array}{l}\text { It has high computational complexity, delays in response time, and requires } \\
\text { fine-tuning of the parameters for high accuracy. The conversion of binary into } \\
\text { a number is very important. This conversion increases the response time. }\end{array}$ & Yes \\
\hline BFA & $\begin{array}{l}\text { This method has reasonable accuracy for } \\
\text { dynamic current profile. }\end{array}$ & $\begin{array}{l}\text { It requires high computation time. More experiments are needed to validate } \\
\text { this technique. }\end{array}$ & No \\
\hline PSO & $\begin{array}{l}\text { This method can measure the SOC online with } \\
\text { reasonable accuracy. }\end{array}$ & $\begin{array}{l}\text { It requires considerable effort to tune the parameters properly. The main } \\
\text { issue of this technique to avoid local optima. This issue can be addressed by } \\
\text { updating the objective function, which results in high computational cost. }\end{array}$ & Yes \\
\hline FL & $\begin{array}{l}\text { This method has good accuracy in different } \\
\text { currents, aging, and temperature conditions. }\end{array}$ & $\begin{array}{l}\text { It has high computation cost and requires high storage size and expensive } \\
\text { data processing units. }\end{array}$ & Yes \\
\hline NN & $\begin{array}{l}\text { This method can provide SOC estimation } \\
\text { under any condition. This is one of the most } \\
\text { suitable methods for SOC estimations in EVs. }\end{array}$ & It also requires large data storage size to save the trained data. & Yes \\
\hline ANFIS & This method has high accuracy. & The storage size should be very high to store trained data. & Yes \\
\hline SVM & $\begin{array}{l}\text { This method performs well in nonlinear and } \\
\text { high dimensional models. }\end{array}$ & This method is time consuming. & Yes \\
\hline MARS & It has reasonable accuracy. & $\begin{array}{l}\text { It has good accuracy at the mid points of the SOC curve. More experiments } \\
\text { are needed to validate this technique. }\end{array}$ & No \\
\hline
\end{tabular}




\section{Future Perspectives of SOC Estimation}

Some future perspectives and recommendations to achieve better performance of BMS of a Li-ion battery are the following:

- There should be some improvement in the round-trip efficiency, depth of discharge and energy density of Li-ion battery. The main concern of its capital cost should be addressed.

- The RC structured ECM model should be improve by adding some more mathematical components, which can more precisely characterize Li-ion battery properties.

- Fusion of different battery models can be a good option to achieve good results.

- Most of the research has been conducted in laboratory premises. So, there is a need of more research in the natural environment where the effects of different conditions such as hot, cold, snowy, rainy, and humid conditions can be checked.

- There are hundreds of cells in the battery pack of EVs. Very few researches have been reported on the estimation of battery packs. Further research is needed to estimate SOC of battery packs.

- The accuracy of the voltage and current sensor has been increased with the development of the technology that can increase the model accuracy. The rapid growth in the field of nanoelectronics has enabled the commercialization of a high-speed controller with a minimal physical size, which can easily tackle the complex mathematical modeling issues in the BMS of EVs. Therefore, the SOC estimation accuracy issue will be diminished soon due to the rapid advances in hardware resources. Owing to the rapid advances in machine learning algorithms, these methodologies are likely to be the future of SOC estimation technology in EVs.

\section{Conclusions}

This study compared the advantages and workings of a Li-ion battery with other ESS in detail. The Li-ion battery has been strongly recommended for EVs because of its high-power density, long lifespan, high energy density, nominal voltage, and relatively low cost. The important features and working cycle of an effective BMS to achieve safe and reliable battery operation in EVs were presented.

This review classified the Li-ion battery-based SOC estimation method into their respective categories according to their nature. A critical explanation, including their merits, limitations, and estimation errors from the literature, was studied in detail. This study concluded that the conventional (direct measurements and bookkeeping) methods are simple and easily implementable, but they suffer from the effect of aging, temperature, sensors drift, and external perturbations. The model-based estimation methods produce good results with high precision. The complexity of the adaptive filters-based method is very high, and it has poor robustness. The machine learning-based SOC estimation methods show the best results among all the methods assessed. The accuracy of these methods is very high under different aging and temperature conditions. These methods require high storage time and a rapid controller for computation. According to the authors, the machine learning algorithms will be the future of SOC estimation technology because of their high accuracy under different challenging conditions and rapid development in nanoelectronics technology. This review paper provides information to manufacturers and researchers developing new SOC methods or updating existing methods.

Author Contributions: M.U.A., A.Z., and H.J.K. conceived the topic. M.U.A., A.Z., and S.H.N. conducted the literature survey and wrote a preliminary version. The paper is revised by S.H. and M.J.A. All the authors were involved in preparing the final version of this manuscript. H.J.K. supervised the whole work.

Funding: This research was supported by Brain Korea 21 Center for Creative Human Resource Development Program for IT Convergence of Pusan National University.

Acknowledgments: This research was supported by Brain Korea 21 Center for Creative Human Resource Development Program for IT Convergence of Pusan National University.

Conflicts of Interest: The authors declare no conflict of interest. 


\section{Appendix A}

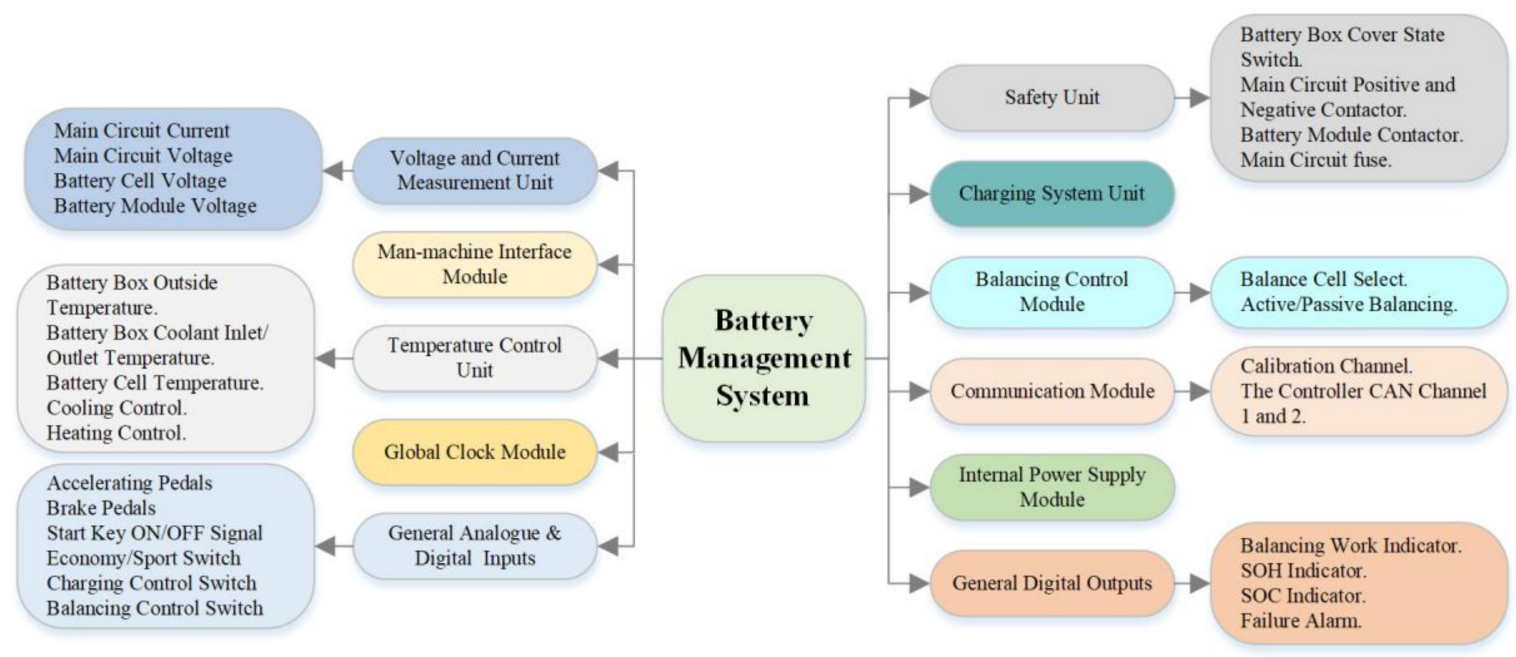

Figure A1. Comprehensive framework for an effective BMS.

\section{References}

1. Jorgensen, $\mathrm{K}$. Technologies for electric, hybrid and hydrogen vehicles: Electricity from renewable energy sources in transport. Utili. Policy 2008, 16, 72-79. [CrossRef]

2. Contestabile, M.; Offer, G.; Slade, R.; Jaeger, F.; Thoennes, M. Battery electric vehicles, hydrogen fuel cells and biofuels. Which will be the winner? Energy Environ. Sci. 2011, 4, 3754-3772. [CrossRef]

3. Umair Ali, M.; Hussain Nengroo, S.; Adil Khan, M.; Zeb, K.; Ahmad Kamran, M.; Kim, H.-J. A real-time simulink interfaced fast-charging methodology of lithium-ion batteries under temperature feedback with fuzzy logic control. Energies 2018, 11, 1122. [CrossRef]

4. Shareef, H.; Islam, M.M.; Mohamed, A. A review of the stage-of-the-art charging technologies, placement methodologies, and impacts of electric vehicles. Renew. Sustain. Energy Rev. 2016, 64, 403-420. [CrossRef]

5. Yong, J.Y.; Ramachandaramurthy, V.K.; Tan, K.M.; Mithulananthan, N. A review on the state-of-the-art technologies of electric vehicle, its impacts and prospects. Renew. Sustain. Energy Rev. 2015, 49, 365-385. [CrossRef]

6. Westbrook, M.H. The Electric Car: Development and Future of Battery, Hybrid and Fuel-Cell Cars; Iet: Stevenage, UK, 2001.

7. Khan, M.A.; Zeb, K.; Sathishkumar, P.; Ali, M.U.; Uddin, W.; Hussain, S.; Ishfaq, M.; Khan, I.; Cho, H.-G.; Kim, H.-J. A novel supercapacitor/lithium-ion hybrid energy system with a fuzzy logic-controlled fast charging and intelligent energy management system. Electronics 2018, 7, 63. [CrossRef]

8. Andersen, P.H.; Mathews, J.A.; Rask, M. Integrating private transport into renewable energy policy: The strategy of creating intelligent recharging grids for electric vehicles. Energy Policy 2009, 37, 2481-2486. [CrossRef]

9. Nengroo, S.; Kamran, M.; Ali, M.; Kim, D.-H.; Kim, M.-S.; Hussain, A.; Kim, H. Dual battery storage system: An optimized strategy for the utilization of renewable photovoltaic energy in the united kingdom. Electronics 2018, 7, 177. [CrossRef]

10. Hu, X.; Zou, C.; Zhang, C.; Li, Y. Technological developments in batteries: A survey of principal roles, types, and management needs. IEEE Power Energy Mag. 2017, 15, 20-31. [CrossRef]

11. Manzetti, S.; Mariasiu, F. Electric vehicle battery technologies: From present state to future systems. Renew. Sustain. Energy Rev. 2015, 51, 1004-1012. [CrossRef]

12. Bilgin, B.; Magne, P.; Malysz, P.; Yang, Y.; Pantelic, V.; Preindl, M.; Korobkine, A.; Jiang, W.; Lawford, M.; Emadi, A. Making the case for electrified transportation. IEEE Trans. Transp. Electrif. 2015, 1, 4-17. [CrossRef]

13. Balchunas, E. US Etfs 2017 Outlook; Bloomberg Intelligence: New York, NY, USA, 2017.

14. Xing, Y.; Ma, E.W.; Tsui, K.L.; Pecht, M. Battery management systems in electric and hybrid vehicles. Energies 2011, 4, 1840-1857. [CrossRef]

15. Lu, L.; Han, X.; Li, J.; Hua, J.; Ouyang, M. A review on the key issues for lithium-ion battery management in electric vehicles. J. Power Sources 2013, 226, 272-288. [CrossRef] 
16. Hannan, M.A.; Lipu, M.H.; Hussain, A.; Mohamed, A. A review of lithium-ion battery state of charge estimation and management system in electric vehicle applications: Challenges and recommendations. Renew. Sustain. Energy Rev. 2017, 78, 834-854. [CrossRef]

17. Zhang, J.; Lee, J. A review on prognostics and health monitoring of li-ion battery. J. Power Sources 2011, 196, 6007-6014. [CrossRef]

18. Zahid, T.; Li, W. A comparative study based on the least square parameter identification method for state of charge estimation of a lifepo4 battery pack using three model-based algorithms for electric vehicles. Energies 2016, 9, 720. [CrossRef]

19. Wang, Q.; Jiang, B.; Li, B.; Yan, Y. A critical review of thermal management models and solutions of lithium-ion batteries for the development of pure electric vehicles. Renew. Sustain. Energy Rev. 2016, 64, 106-128. [CrossRef]

20. Ralon, P.; Taylor, M.; Ilas, A.; Diaz-Bone, H.; Kairies, K. Electricity Storage and Renewables: Costs and Markets to 2030; International Renewable Energy Agency: Abu Dhabi, United Arab Emirates, 2017.

21. Safa, M.; Chamaani, A.; Chawla, N.; El-Zahab, B. Polymeric ionic liquid gel electrolyte for room temperature lithium battery applications. Electrochimica Acta 2016, 213, 587-593. [CrossRef]

22. Chamaani, A.; Safa, M.; Chawla, N.; El-Zahab, B. Composite gel polymer electrolyte for improved cyclability in lithium-oxygen batteries. ACS Appl. Mater. Interfaces 2017, 9, 33819-33826. [CrossRef]

23. Safa, M.; Hao, Y.; Chamaani, A.; Adelowo, E.; Chawla, N.; Wang, C.; El-Zahab, B. Capacity fading mechanism in lithium-sulfur battery using poly (ionic liquid) gel electrolyte. Electrochimica Acta 2017, 258, 1284-1292. [CrossRef]

24. Chamaani, A.; Safa, M.; Chawla, N.; Herndon, M.; El-Zahab, B. Stabilizing effect of ion complex formation in lithium-oxygen battery electrolytes. J. Electroanal. Chem. 2018, 815, 143-150. [CrossRef]

25. Snihir, I.; Rey, W.; Verbitskiy, E.; Belfadhel-Ayeb, A.; Notten, P.H. Battery open-circuit voltage estimation by a method of statistical analysis. J. Power Sources 2006, 159, 1484-1487. [CrossRef]

26. Tang, X.; Wang, Y.; Chen, Z. A method for state-of-charge estimation of lifepo4 batteries based on a dual-circuit state observer. J. Power Sources 2015, 296, 23-29. [CrossRef]

27. Roscher, M.A.; Sauer, D.U. Dynamic electric behavior and open-circuit-voltage modeling of lifepo4-based lithium ion secondary batteries. J. Power Sources 2011, 196, 331-336. [CrossRef]

28. Truchot, C.; Dubarry, M.; Liaw, B.Y. State-of-charge estimation and uncertainty for lithium-ion battery strings. Appl. Energy 2014, 119, 218-227. [CrossRef]

29. Pop, V.; Bergveld, H.J.; het Veld, J.O.; Regtien, P.P.; Danilov, D.; Notten, P. Modeling battery behavior for accurate state-of-charge indication. J. Electrochem. Soc. 2006, 153, A2013-A2022. [CrossRef]

30. Yang, Y.P.; Liu, J.J.; Tsai, C.H. Improved estimation of residual capacity of batteries for electric vehicles. J. Chin. Inst. Eng. 2008, 31, 313-322. [CrossRef]

31. Coleman, M.; Lee, C.K.; Zhu, C.; Hurley, W.G. State-of-charge determination from emf voltage estimation: Using impedance, terminal voltage, and current for lead-acid and lithium-ion batteries. IEEE Trans. Ind. Electron. 2007, 54, 2550-2557. [CrossRef]

32. Waag, W.; Sauer, D.U. Adaptive estimation of the electromotive force of the lithium-ion battery after current interruption for an accurate state-of-charge and capacity determination. Appl. Energy 2013, 111, 416-427. [CrossRef]

33. Wang, H.; Liu, Y.; Fu, H.; Li, G. Estimation of state of charge of batteries for electric vehicles. Int. J. Control Autom. 2013, 6, 185-194.

34. Bao, Y.; Dong, W.; Wang, D. Online internal resistance measurement application in lithium ion battery capacity and state of charge estimation. Energies 2018, 11, 1073. [CrossRef]

35. Barcellona, S.; Grillo, S.; Piegari, L. A simple battery model for ev range prediction: Theory and experimental validation. In Proceedings of the Electrical Systems for Aircraft, Railway, Ship Propulsion and Road Vehicles \& International Transportation Electrification Conference (ESARS-ITEC), Toulouse, France, 2-4 November 2016.

36. Westerhoff, U.; Kroker, T.; Kurbach, K.; Kurrat, M. Electrochemical impedance spectroscopy based estimation of the state of charge of lithium-ion batteries. J. Energy Storage 2016, 8, 244-256. [CrossRef]

37. Xu, J.; Mi, C.C.; Cao, B.; Cao, J. A new method to estimate the state of charge of lithium-ion batteries based on the battery impedance model. J. Power Sources 2013, 233, 277-284. [CrossRef]

38. Wu, S.-L.; Chen, H.-C.; Tsai, M.-Y. Ac impedance-based online state-of-charge estimation for li-ion batteries. Sens. Mater. 2018, 30, 539-550. [CrossRef] 
39. Guha, A.; Patra, A.; Vaisakh, K. Remaining useful life estimation of lithium-ion batteries based on the internal resistance growth model. In Proceedings of the Control Conference (ICC), Assam, India, 4-6 January 2017.

40. Rivera-Barrera, J.; Munoz-Galeano, N.; Sarmiento-Maldonado, H. Soc estimation for lithium-ion batteries: Review and future challenges. Electronics 2017, 6, 102. [CrossRef]

41. Zhang, Y.; Song, W.; Lin, S.; Feng, Z. A novel model of the initial state of charge estimation for lifepo4 batteries. J. Power Sources 2014, 248, 1028-1033. [CrossRef]

42. Wu, T.-H.; Moo, C.-S. State-of-charge estimation with state-of-health calibration for lithium-ion batteries. Energies 2017, 10, 987.

43. Xie, J.; Ma, J.; Bai, K. Enhanced coulomb counting method for state-of-charge estimation of lithium-ion batteries based on peukert's law and coulombic efficiency. J. Power Electron. 2018, 18, 910-922.

44. Xu, J.; Gao, M.; He, Z.; Han, Q.; Wang, X. State of charge estimation online based on ekf-ah method for lithium-ion power battery. In Proceedings of the Image and Signal Processing, Tianjin, China, 17-19 October 2009.

45. Cheng, K.W.E.; Divakar, B.; Wu, H.; Ding, K.; Ho, H.F. Battery-management system (bms) and soc development for electrical vehicles. IEEE Trans. on Veh. Technol. 2011, 60, 76-88. [CrossRef]

46. Gu, W.; Wang, C. Thermal-electrochemical modeling of battery systems. J. Electrochem. Soc. 2000, 147, 2910-2922. [CrossRef]

47. Di Domenico, D.; Fiengo, G.; Stefanopoulou, A. Lithium-ion battery state of charge estimation with a kalman filter based on a electrochemical model. In Proceedings of the IEEE International Conference on Control Applications, San Antonio, TX, USA, 3-5 September 2008.

48. Rahman, M.A.; Anwar, S.; Izadian, A. Electrochemical model parameter identification of a lithium-ion battery using particle swarm optimization method. J. Power Sources 2016, 307, 86-97. [CrossRef]

49. Li, J.; Wang, L.; Lyu, C.; Pecht, M. State of charge estimation based on a simplified electrochemical model for a single licoo2 battery and battery pack. Energy 2017, 133, 572-583. [CrossRef]

50. Meng, J.; Luo, G.; Ricco, M.; Swierczynski, M.; Stroe, D.-I.; Teodorescu, R. Overview of lithium-ion battery modeling methods for state-of-charge estimation in electrical vehicles. Appl. Sciences 2018, 8, 659. [CrossRef]

51. Zhang, X.; Zhang, W.; Lei, G. A review of li-ion battery equivalent circuit models. Trans. Electr. Electron. Mater. 2016, 17, 311-316. [CrossRef]

52. He, H.; Zhang, X.; Xiong, R.; Xu, Y.; Guo, H. Online model-based estimation of state-of-charge and open-circuit voltage of lithium-ion batteries in electric vehicles. Energy 2012, 39, 310-318. [CrossRef]

53. Hu, X.; Li, S.; Peng, H. A comparative study of equivalent circuit models for li-ion batteries. J. Power Sources 2012, 198, 359-367. [CrossRef]

54. Simon, D. Optimal State Estimation: Kalman, $h$ Infinity, and Nonlinear Approaches; John Wiley \& Sons: Hoboken, NJ, USA, 2006.

55. Zhang, F.; Liu, G.; Fang, L.; Wang, H. Estimation of battery state of charge with ho observer: Applied to a robot for inspecting power transmission lines. IEEE Trans. Ind.. Electron. 2012, 59, 1086. [CrossRef]

56. Zhang, Y.; Zhang, C.; Zhang, X. State-of-charge estimation of the lithium-ion battery system with time-varying parameter for hybrid electric vehicles. IET Control Theory Appl. 2014, 8, 160-167. [CrossRef]

57. Zhu, Q.; Xiong, N.; Yang, M.-L.; Huang, R.-S.; Hu, G.-D. State of charge estimation for lithium-ion battery based on nonlinear observer: An ho method. Energies 2017, 10, 679. [CrossRef]

58. Zhang, Y.; Xiong, R.; He, H.; Shen, W. A lithium-ion battery pack state of charge and state of energy estimation algorithms using a hardware-in-the-loop validation. IEEE Trans. Power Electron. 2017, 32, 4421-4431. [CrossRef]

59. Xiong, R.; Yu, Q.; Wang, L.Y.; Lin, C. A novel method to obtain the open circuit voltage for the state of charge of lithium ion batteries in electric vehicles by using h infinity filter. Appl. Energy 2017, 207, 346-353. [CrossRef]

60. Xia, B.; Zhang, Z.; Lao, Z.; Wang, W.; Sun, W.; Lai, Y.; Wang, M. Strong tracking of a h-infinity filter in lithium-ion battery state of charge estimation. Energies 2018, 11, 1481. [CrossRef]

61. Liu, Z.; Dang, X.; Sun, H. Online state of charge estimation for lithium-ion battery by combining incremental autoregressive and moving average modeling with adaptive h-infinity filter. Math. Probl. Eng. 2018, 2018. [CrossRef]

62. Alfi, A.; Charkhgard, M.; Zarif, M.H. Hybrid state of charge estimation for lithium-ion batteries: Design and implementation. IET Power Electron. 2014, 7, 2758-2764. [CrossRef] 
63. Lin, C.; Mu, H.; Xiong, R.; Shen, W. A novel multi-model probability battery state of charge estimation approach for electric vehicles using h-infinity algorithm. Appl. energy 2016, 166, 76-83. [CrossRef]

64. Yu, Q.; Xiong, R.; Lin, C.; Shen, W.; Deng, J. Lithium-ion battery parameters and state-of-charge joint estimation based on h-infinity and unscented kalman filters. IEEE Trans. Veh. Technol. 2017, 66, 8693-8701. [CrossRef]

65. Charkhgard, M.; Zarif, M.H. Design of adaptiveh $\infty$ filter for implementing on state-of-charge estimation based on battery state-of-charge-varying modelling. IET Power Electron. 2015, 8, 1825-1833. [CrossRef]

66. Lin, C.; Yu, Q.; Xiong, R.; Wang, L.Y. A study on the impact of open circuit voltage tests on state of charge estimation for lithium-ion batteries. Appl. Energy 2017, 205, 892-902. [CrossRef]

67. Chen, C.; Sun, F.; Xiong, R.; He, H. A novel dual h infinity filters based battery parameter and state estimation approach for electric vehicles application. Energy Procedia 2016, 103, 375-380. [CrossRef]

68. Gibbs, B.P. Advanced Kalmanfiltering, Least-Squaresand Modeling; Wiley: Hoboken, NJ, USA, 2011.

69. Haykin, S. Adaptive Filter Theory, 3rd ed.; Printice Hall: Upper Saddle River, NJ, USA, 1996.

70. Haykin, S. Kalman Filtering and Neural Networks; John Wiley \& Sons: Hoboken, NJ, USA, 2004.

71. Plett, G.L. Sigma-point kalman filtering for battery management systems of lipb-based hev battery packs: Part 1: Introduction and state estimation. J. Power Sources 2006, 161, 1356-1368. [CrossRef]

72. Yatsui, M.W.; Bai, H. Kalman filter based state-of-charge estimation for lithium-ion batteries in hybrid electric vehicles using pulse charging. In Proceedings of the 2011 IEEE Vehicle Power and Propulsion Conference (VPPC 2011), Chicago, IL, USA, 6-9 September 2011.

73. Urbain, M.; Rael, S.; Davat, B.; Desprez, P. State estimation of a lithium-ion battery through kalman filter. In Proceedings of the 2011 IEEE Power Electronics Specialists Conference (PESC 2007), Orlando, FL, USA, 17-21 June 2007.

74. Ting, T.; Man, K.L.; Lim, E.G.; Leach, M. Tuning of kalman filter parameters via genetic algorithm for state-of-charge estimation in battery management system. Sci. World J. 2014, 2014. [CrossRef]

75. Zhao, W.; Kong, X.; Wang, C. Combined estimation of the state of charge of a lithium battery based on a back-propagation-adaptive kalman filter algorithm. Proc. Inst. Mech. Eng. Part D: J. Autom. Eng. 2018, 232, 357-366. [CrossRef]

76. Cui, X.; Jing, Z.; Luo, M.; Guo, Y.; Qiao, H. A new method for state of charge estimation of lithium-ion batteries using square root cubature kalman filter. Energies 2018, 11, 209. [CrossRef]

77. Chen, L.; Xu, L.; Wang, R. State of charge estimation for lithium-ion battery by using dual square root cubature kalman filter. Mathe. Probl. Eng. 2017, 2017. [CrossRef]

78. Huang, C.; Wang, Z.; Zhao, Z.; Wang, L.; Lai, C.S.; Wang, D. Robustness evaluation of extended and unscented kalman filter for battery state of charge estimation. IEEE Access 2018. [CrossRef]

79. Lee, S.; Kim, J.; Lee, J.; Cho, B.H. The state and parameter estimation of an li-ion battery using a new ocv-soc concept. In Proceedings of the 2011 IEEE Power Electronics Specialists Conference (PESC 2007), Orlando, FL, USA, 17-21 June 2007.

80. He, H.; Xiong, R.; Guo, H. Online estimation of model parameters and state-of-charge of lifepo4 batteries in electric vehicles. Appl. Energy 2012, 89, 413-420. [CrossRef]

81. Xiong, R.; He, H.; Sun, F.; Zhao, K. Evaluation on state of charge estimation of batteries with adaptive extended kalman filter by experiment approach. IEEE Tran. Veh. Technol. 2013, 62, 108-117. [CrossRef]

82. Jiang, C.; Taylor, A.; Duan, C.; Bai, K. Extended kalman filter based battery state of charge (soc) estimation for electric vehicles. In Proceedings of the Transportation Electrification Conference and Expo (ITEC), Detroit, MI, USA, 16-19 June 2013.

83. He, H.; Xiong, R.; Zhang, X.; Sun, F.; Fan, J. State-of-charge estimation of the lithium-ion battery using an adaptive extended kalman filter based on an improved thevenin model. IEEE Trans. Veh. Technol. 2011, 60, $1461-1469$.

84. Zhu, Z.; Sun, J.; Liu, D. Online state of charge ekf estimation for lifepo 4 battery management systems. In Proceedings of the Intelligent Signal Processing and Communications Systems (ISPACS), Tamsui, New Taipei City, Taiwan, 4-7 November 2012.

85. Chen, Z.; Fu, Y.; Mi, C.C. State of charge estimation of lithium-ion batteries in electric drive vehicles using extended kalman filtering. IEEE Trans. Veh. Technol. 2013, 62, 1020-1030. [CrossRef]

86. Xie, J.; Ma, J.; Bai, K. State-of-charge estimators considering temperature effect, hysteresis potential, and thermal evolution for lifepo4 batteries. Int. J. Energy Res. 2018. [CrossRef] 
87. Mastali, M.; Vazquez-Arenas, J.; Fraser, R.; Fowler, M.; Afshar, S.; Stevens, M. Battery state of the charge estimation using kalman filtering. J. Power Sources 2013, 239, 294-307. [CrossRef]

88. Hu, X.; Sun, F.; Zou, Y. Comparison between two model-based algorithms for li-ion battery soc estimation in electric vehicles. Simul. Model. Pract. Theory 2013, 34, 1-11. [CrossRef]

89. Sepasi, S.; Ghorbani, R.; Liaw, B.Y. Improved extended kalman filter for state of charge estimation of battery pack. J. Power Sources 2014, 255, 368-376. [CrossRef]

90. Wang, S.; Fernandez, C.; Shang, L.; Li, Z.; Li, J. Online state of charge estimation for the aerial lithium-ion battery packs based on the improved extended kalman filter method. J. Energy Storage 2017, 9, 69-83. [CrossRef]

91. Xiong, R.; Sun, F.; Chen, Z.; He, H. A data-driven multi-scale extended kalman filtering based parameter and state estimation approach of lithium-ion olymer battery in electric vehicles. Appl. Energy 2014, 113, 463-476. [CrossRef]

92. Yang, S.; Deng, C.; Zhang, Y.; He, Y. State of charge estimation for lithium-ion battery with a temperature-compensated model. Energies 2017, 10, 1560. [CrossRef]

93. Pan, H.; Lü, Z.; Lin, W.; Li, J.; Chen, L. State of charge estimation of lithium-ion batteries using a grey extended kalman filter and a novel open-circuit voltage model. Energy 2017, 138, 764-775. [CrossRef]

94. Xu, L.; Wang, J.; Chen, Q. Kalman filtering state of charge estimation for battery management system based on a stochastic fuzzy neural network battery model. Energy Convers. Manag. 2012, 53, 33-39. [CrossRef]

95. He, W.; Williard, N.; Chen, C.; Pecht, M. State of charge estimation for electric vehicle batteries using unscented kalman filtering. Microelectron. Reliab. 2013, 53, 840-847. [CrossRef]

96. Tian, Y.; Xia, B.; Sun, W.; Xu, Z.; Zheng, W. A modified model based state of charge estimation of power lithium-ion batteries using unscented kalman filter. J. Power Sources 2014, 270, 619-626. [CrossRef]

97. Wang, T.; Chen, S.; Ren, H.; Zhao, Y. Model-based unscented kalman filter observer design for lithium-ion battery state of charge estimation. Int. J. Energy Res. 2018, 42, 1603-1614. [CrossRef]

98. Yang, F.; Xing, Y.; Wang, D.; Tsui, K.-L. A comparative study of three model-based algorithms for estimating state-of-charge of lithium-ion batteries under a new combined dynamic loading profile. Appl. Energy 2016, 164, 387-399. [CrossRef]

99. Zheng, F.; Xing, Y.; Jiang, J.; Sun, B.; Kim, J.; Pecht, M. Influence of different open circuit voltage tests on state of charge online estimation for lithium-ion batteries. Appl. energy 2016, 183, 513-525. [CrossRef]

100. Sun, F.; Hu, X.; Zou, Y.; Li, S. Adaptive unscented kalman filtering for state of charge estimation of a lithium-ion battery for electric vehicles. Energy 2011, 36, 3531-3540. [CrossRef]

101. Du, J.; Liu, Z.; Wang, Y. State of charge estimation for li-ion battery based on model from extreme learning machine. Control Eng. Pract. 2014, 26, 11-19. [CrossRef]

102. Partovibakhsh, M.; Liu, G. An adaptive unscented kalman filtering approach for online estimation of model parameters and state-of-charge of lithium-ion batteries for autonomous mobile robots. IEEE Trans. Control Syst. Technol. 2015, 23, 357-363. [CrossRef]

103. Cai, M.; Chen, W.; Tan, X. Battery state-of-charge estimation based on a dual unscented kalman filter and fractional variable-order model. Energies 2017, 10, 1577. [CrossRef]

104. Liu, S.; Cui, N.; Zhang, C. An adaptive square root unscented kalman filter approach for state of charge estimation of lithium-ion batteries. Energies 2017, 10, 1345.

105. Peng, S.; Chen, C.; Shi, H.; Yao, Z. State of charge estimation of battery energy storage systems based on adaptive unscented kalman filter with a noise statistics estimator. IEEE Access 2017, 5, 13202-13212. [CrossRef]

106. Chen, Y.; Huang, D.; Zhu, Q.; Liu, W.; Liu, C.; Xiong, N. A new state of charge estimation algorithm for lithium-ion batteries based on the fractional unscented kalman filter. Energies 2017, 10, 1313. [CrossRef]

107. Li, Y.; Wang, C.; Gong, J. A wavelet transform-adaptive unscented kalman filter approach for state of charge estimation of lifepo4 battery. Int. J. Energy Res. 2018, 42, 587-600. [CrossRef]

108. Li, G.; Peng, K.; Li, B. State-of-charge estimation for lithium-ion battery using a combined method. J. Power Electron. 2018, 18, 129-136.

109. Van Der Merwe, R. Sigma-Point Kalman Filters for Probabilistic Inference in Dynamic State-Space Models; Oregon Health \& Science University Beaverton: Beaverton, OR, USA, 2004.

110. Plett, G.L. Sigma-point kalman filtering for battery management systems of lipb-based hev battery packs part 2: Simultaneous state and parameter estimation. J. Power Sources 2006, 161, 1369-1384. [CrossRef] 
111. He, Z.; Liu, Y.; Gao, M.; Wang, C. A joint model and soc estimation method for lithium battery based on the sigma point kf. In Proceedings of the Transportation Electrification Conference and Expo (ITEC), Dearborn, MI, USA, 18-20 June 2012.

112. Li, J.; Barillas, J.K.; Guenther, C.; Danzer, M.A. A comparative study of state of charge estimation algorithms for lifepo4 batteries used in electric vehicles. J. Power Sources 2013, 230, 244-250. [CrossRef]

113. Li, D.; Ouyang, J.; Li, H.; Wan, J. State of charge estimation for limn2o4 power battery based on strong tracking sigma point kalman filter. J. Sources 2015, 279, 439-449. [CrossRef]

114. Gao, M.; Liu, Y.; He, Z. Battery state of charge online estimation based on particle filter. In Proceedings of the 4th International Congress on Image and Signal Processing (CISP), Shanghai, China, 15-17 October 2011.

115. Schwunk, S.; Armbruster, N.; Straub, S.; Kehl, J.; Vetter, M. Particle filter for state of charge and state of health estimation for lithium-iron phosphate batteries. J. Power Sources 2013, 239, 705-710. [CrossRef]

116. Tulsyan, A.; Tsai, Y.; Gopaluni, R.B.; Braatz, R.D. State-of-charge estimation in lithium-ion batteries: A particle filter approach. J. Power Sources 2016, 331, 208-223. [CrossRef]

117. He, Y.; Liu, X.; Zhang, C.; Chen, Z. A new model for state-of-charge (soc) estimation for high-power li-ion batteries. Appl. Energy 2013, 101, 808-814. [CrossRef]

118. Burgos-Mellado, C.; Orchard, M.E.; Kazerani, M.; Cárdenas, R.; Sáez, D. Particle-filtering-based estimation of maximum available power state in lithium-ion batteries. Appl. Energy 2016, 161, 349-363. [CrossRef]

119. Zhou, D.; Zhang, K.; Ravey, A.; Gao, F.; Miraoui, A. Online estimation of lithium polymer batteries state-of-charge using particle filter-based data fusion with multimodels approach. IEEE Trans. Ind. Appl. 2016, 52, 2582-2595. [CrossRef]

120. Du, Q.; Han, Q.; Zhang, Y.; Liu, Z.; Tian, S.; Zhang, Z. Adopting combined strategies to make state of charge (soc) estimation for practical use. J. Renew. Sustain. Energy 2018, 10, 034102. [CrossRef]

121. Xia, B.; Sun, Z.; Zhang, R.; Lao, Z. A cubature particle filter algorithm to estimate the state of the charge of lithium-ion batteries based on a second-order equivalent circuit model. Energies 2017, 10, 457. [CrossRef]

122. Li, B.; Peng, K.; Li, G. State-of-charge estimation for lithium-ion battery using the gauss-hermite particle filter technique. J. Renew. Sustain. Energy 2018, 10, 014105. [CrossRef]

123. Ye, M.; Guo, H.; Xiong, R.; Yu, Q. A double-scale and adaptive particle filter-based online parameter and state of charge estimation method for lithium-ion batteries. Energy 2018, 144, 789-799. [CrossRef]

124. Hu, X.; Sun, F.; Zou, Y.; Peng, H. Online estimation of an electric vehicle lithium-ion battery using recursive least squares with forgetting. In Proceedings of the American Control Conference (ACC), San Francisco, CA, USA, 29 June-1 July 2011.

125. Eddahech, A.; Briat, O.; Vinassa, J.-M. Adaptive voltage estimation for ev li-ion cell based on artificial neural networks state-of-charge meter. In Proceedings of the 2012 IEEE International Symposium on Industrial Electronics (ISIE), Hangzhou, China, 28-31 May 2012.

126. Lim, K.; Bastawrous, H.A.; Duong, V.-H.; See, K.W.; Zhang, P.; Dou, S.X. Fading kalman filter-based real-time state of charge estimation in lifepo4 battery-powered electric vehicles. Appl. Energy 2016, 169, 40-48. [CrossRef]

127. Lotfi, N.; Landers, R.G.; Li, J.; Park, J. Reduced-order electrochemical model-based soc observer with output model uncertainty estimation. IEEE Trans. Control Syst. Technol. 2017, 25, 1217-1230. [CrossRef]

128. Safwat, I.M.; Li, W.; Wu, X. A novel methodology for estimating state-of-charge of li-ion batteries using advanced parameters estimation. Energies 2017, 10, 1751. [CrossRef]

129. Duong, V.-H.; Bastawrous, H.A.; See, K.W. Accurate approach to the temperature effect on state of charge estimation in the lifepo4 battery under dynamic load operation. Appl. Energy 2017, 204, 560-571. [CrossRef]

130. Xia, B.; Lao, Z.; Zhang, R.; Tian, Y.; Chen, G.; Sun, Z.; Wang, W.; Sun, W.; Lai, Y.; Wang, M. Online parameter identification and state of charge estimation of lithium-ion batteries based on forgetting factor recursive least squares and nonlinear kalman filter. Energies 2018, 11, 3. [CrossRef]

131. Shen, P.; Ouyang, M.; Lu, L.; Li, J.; Feng, X. The co-estimation of state of charge, state of health, and state of function for lithium-ion batteries in electric vehicles. IEEE Trans. Veh. Technol. 2018, 67, 92-103. [CrossRef]

132. Ali, M.; Kamran, M.; Kumar, P.; Nengroo, S.; Khan, M.; Hussain, A.; Kim, H.-J. An online data-driven model identification and adaptive state of charge estimation approach for lithium-ion-batteries using the lagrange multiplier method. Energies 2018, 11, 2940. [CrossRef]

133. Zhang, C.; Allafi, W.; Dinh, Q.; Ascencio, P.; Marco, J. Online estimation of battery equivalent circuit model parameters and state of charge using decoupled least squares technique. Energy 2018, 142, 678-688. [CrossRef] 
134. Zhang, R.; Xia, B.; Li, B.; Cao, L.; Lai, Y.; Zheng, W.; Wang, H.; Wang, W. State of the art of lithium-ion battery soc estimation for electrical vehicles. Energies 2018, 11, 1820. [CrossRef]

135. Xia, B.; Chen, C.; Tian, Y.; Sun, W.; Xu, Z.; Zheng, W. A novel method for state of charge estimation of lithium-ion batteries using a nonlinear observer. J. Power Sources 2014, 270, 359-366. [CrossRef]

136. Tian, Y.; Li, D.; Tian, J.; Xia, B. State of charge estimation of lithium-ion batteries using an optimal adaptive gain nonlinear observer. Electrochimica Acta 2017, 225, 225-234. [CrossRef]

137. Ma, Y.; Li, B.; Li, G.; Zhang, J.; Chen, H. A nonlinear observer approach of soc estimation based on hysteresis model for lithium-ion battery. IEEE/CAA J. Autom. Sinica 2017, 4, 195-204. [CrossRef]

138. Li, W.; Liang, L.; Liu, W.; Wu, X. State of charge estimation of lithium-ion batteries using a discrete-time nonlinear observer. IEEE Trans. Ind. Electron. 2017, 64, 8557-8565. [CrossRef]

139. Chen, J.; Ouyang, Q.; Xu, C.; Su, H. Neural network-based state of charge observer design for lithium-ion batteries. IEEE Trans. Control Syst. Technol. 2018, 26, 313-320. [CrossRef]

140. Kim, I.-S. The novel state of charge estimation method for lithium battery using sliding mode observer. J. Power Sources 2006, 163, 584-590. [CrossRef]

141. Kim, I.-S. Nonlinear state of charge estimator for hybrid electric vehicle battery. IEEE Trans. Power Electron. 2008, 23, 2027-2034.

142. Chen, X.; Shen, W.; Cao, Z.; Kapoor, A. Sliding mode observer for state of charge estimation based on battery equivalent circuit in electric vehicles. Aust. J. Electr. and Electron. Eng. 2012, 9, 225-234. [CrossRef]

143. Ning, B.; Xu, J.; Cao, B.; Wang, B.; Xu, G. A sliding mode observer soc estimation method based on parameter adaptive battery model. Energy Procedia 2016, 88, 619-626. [CrossRef]

144. Ma, Y.; Li, B.; Xie, Y.; Chen, H. Estimating the state of charge of lithium-ion battery based on sliding mode observer. IFAC-PapersOnLine 2016, 49, 54-61. [CrossRef]

145. Xia, B.; Zheng, W.; Zhang, R.; Lao, Z.; Sun, Z. A novel observer for lithium-ion battery state of charge estimation in electric vehicles based on a second-order equivalent circuit model. Energies 2017, 10, 1150. [CrossRef]

146. Du, J.; Liu, Z.; Wang, Y.; Wen, C. An adaptive sliding mode observer for lithium-ion battery state of charge and state of health estimation in electric vehicles. Control Eng. Pract. 2016, 54, 81-90. [CrossRef]

147. Kim, D.; Koo, K.; Jeong, J.J.; Goh, T.; Kim, S.W. Second-order discrete-time sliding mode observer for state of charge determination based on a dynamic resistance li-ion battery model. Energies 2013, 6, 5538-5551. [CrossRef]

148. Chen, Y.; Ma, Y.; Chen, H. State of charge and state of health estimation for lithium-ion battery through dual sliding mode observer based on amesim-simulink co-simulation. J. Renew. Sustain. Energy 2018, 10, 034103. [CrossRef]

149. Chen, X.; Shen, W.; Cao, Z.; Kapoor, A. Adaptive gain sliding mode observer for state of charge estimation based on combined battery equivalent circuit model. Comput. Chem. Eng. 2014, 64, 114-123. [CrossRef]

150. Chen, X.; Shen, W.; Cao, Z.; Kapoor, A. A novel approach for state of charge estimation based on adaptive switching gain sliding mode observer in electric vehicles. J. Power Sources 2014, 246, 667-678. [CrossRef]

151. Huangfu, Y.; Xu, J.; Zhao, D.; Liu, Y.; Gao, F. A novel battery state of charge estimation method based on a super-twisting sliding mode observer. Energies 2018, 11, 1211. [CrossRef]

152. Zhong, Q.; Zhong, F.; Cheng, J.; Li, H.; Zhong, S. State of charge estimation of lithium-ion batteries using fractional order sliding mode observer. ISA Trans. 2017, 66, 448-459. [CrossRef]

153. Kim, D.; Goh, T.; Park, M.; Kim, S.W. Fuzzy sliding mode observer with grey prediction for the estimation of the state-of-charge of a lithium-ion battery. Energies 2015, 8, 12409-12428. [CrossRef]

154. Xu, J.; Mi, C.C.; Cao, B.; Deng, J.; Chen, Z.; Li, S. The state of charge estimation of lithium-ion batteries based on a proportional-integral observer. IEEE Trans. Veh. Technol. 2014, 63, 1614-1621.

155. Xu, J.; Cao, B.; Chen, Z.; Zou, Z. An online state of charge estimation method with reduced prior battery testing information. Int. J. Electr. Power Energy Syst. 2014, 63, 178-184. [CrossRef]

156. Xu, J.; Cao, B.; Cao, J.; Zou, Z.; Mi, C.C.; Chen, Z. A comparison study of the model based soc estimation methods for lithium-ion batteries. In Proceedings of the Vehicle Power and Propulsion Conference (VPPC), Beijing, China, 15-18 October 2013.

157. Zou, Z.; Xu, J.; Mi, C.; Cao, B.; Chen, Z. Evaluation of model based state of charge estimation methods for lithium-ion batteries. Energies 2014, 7, 5065-5082. [CrossRef] 
158. Zheng, L.; Zhang, L.; Zhu, J.; Wang, G.; Jiang, J. Co-estimation of state-of-charge, capacity and resistance for lithium-ion batteries based on a high-fidelity electrochemical model. Appl. Energy 2016, 180, 424-434. [CrossRef]

159. Wei, J.; Dong, G.; Chen, Z. On-board adaptive model for state of charge estimation of lithium-ion batteries based on kalman filter with proportional integral-based error adjustment. J. Power Sources 2017, 365, 308-319. [CrossRef]

160. Meng, J.; Ricco, M.; Acharya, A.B.; Luo, G.; Swierczynski, M.; Stroe, D.-I.; Teodorescu, R. Low-complexity online estimation for lifepo 4 battery state of charge in electric vehicles. J. Power Sources 2018, 395, 280-288. [CrossRef]

161. Du, T.; Vas, P.; Stronach, F. Design and application of extended observers for joint state and parameter estimation in high-performance ac drives. IEE Proc. Electr. Power Appl. 1995, 142, 71-78. [CrossRef]

162. Hu, X.; Sun, F.; Zou, Y. Estimation of state of charge of a lithium-ion battery pack for electric vehicles using an adaptive luenberger observer. Energies 2010, 3, 1586-1603. [CrossRef]

163. Tanim, T.R.; Rahn, C.D.; Wang, C.-Y. State of charge estimation of a lithium ion cell based on a temperature dependent and electrolyte enhanced single particle model. Energy 2015, 80, 731-739. [CrossRef]

164. Tang, X.; Liu, B.; Lv, Z.; Gao, F. Observer based battery soc estimation: Using multi-gain-switching approach. Appl. Energy 2017, 204, 1275-1283. [CrossRef]

165. Zheng, Y.; Lu, L.; Han, X.; Li, J.; Ouyang, M. Lifepo4 battery pack capacity estimation for electric vehicles based on charging cell voltage curve transformation. J. Power Sources 2013, 226, 33-41. [CrossRef]

166. Chen, Z.; Mi, C.C.; Fu, Y.; Xu, J.; Gong, X. Online battery state of health estimation based on genetic algorithm for electric and hybrid vehicle applications. J. Power Sources 2013, 240, 184-192. [CrossRef]

167. Lin, C.; Zhang, X.; Xiong, R.; Zhou, F. A novel approach to state of charge estimation using extended kalman filtering for lithium-ion batteries in electric vehicles. In Proceedings of the IEEE Transportation Electrification Conference \& Expo 2014 (ITEC Asia-Pacific), Beijing, China, August 31-3 September 2014.

168. Khan, M.R.; Mulder, G.; Van Mierlo, J. An online framework for state of charge determination of battery systems using combined system identification approach. J. Power Sources 2014, 246, 629-641. [CrossRef]

169. Chen, L.; Wang, Z.; Lü, Z.; Li, J.; Ji, B.; Wei, H.; Pan, H. A novel state-of-charge estimation method of lithium-ion batteries combining the grey model and genetic algorithms. IEEE Trans. Power Electron. 2018, 33, 8797-8807. [CrossRef]

170. Blaifi, S.; Moulahoum, S.; Colak, I.; Merrouche, W. An enhanced dynamic model of battery using genetic algorithm suitable for photovoltaic applications. Appl. Energy 2016, 169, 888-898. [CrossRef]

171. Mu, H.; Xiong, R.; Zheng, H.; Chang, Y.; Chen, Z. A novel fractional order model based state-of-charge estimation method for lithium-ion battery. Appl. Energy 2017, 207, 384-393. [CrossRef]

172. Yang, R.; Xiong, R.; He, H.; Mu, H.; Wang, C. A novel method on estimating the degradation and state of charge of lithium-ion batteries used for electrical vehicles. Appl. Energy 2017, 207, 336-345. [CrossRef]

173. Jhankal, N.K.; Adhyaru, D. Bacterial foraging optimization algorithm: A derivative free technique. In Proceedings of the 2011 Nirma University International Conference on Engineering (NUiCONE), Gujarat, India, 8-10 December 2011.

174. Kar, A.K. Bio inspired computing-a review of algorithms and scope of applications. Expert Syst. Appl. 2016, 59, 20-32. [CrossRef]

175. Ma, Y.; Ru, J.; Yin, M.; Chen, H.; Zheng, W. Electrochemical modeling and parameter identification based on bacterial foraging optimization algorithm for lithium-ion batteries. J. Appl. Electrochem. 2016, 46, 1119-1131. [CrossRef]

176. Eberhart, R.C.; Shi, Y.; Kennedy, J. Swarm Intelligence (Morgan Kaufmann Series in Evolutionary Computation); Morgan Kaufmann Publishers: Burlington, MA, USA, 2001.

177. Ali, M.U.; Habib, B.; Iqbal, M. Fixed head short term hydro thermal scheduling using improved particle swarm optimization. Nucleus (Islamabad) 2015, 52, 107-114.

178. Sheikhan, M.; Pardis, R.; Gharavian, D. State of charge neural computational models for high energy density batteries in electric vehicles. Neural Comput. Appl. 2013, 22, 1171-1180. [CrossRef]

179. Ismail, N.H.F.; Toha, S.F. State of charge estimation of a lithium-ion battery for electric vehicle based on particle swarm optimization. In Proceedings of the IEEE International Conference on Smart Instrumentation, Measurement and Applications (ICSIMA), Kuala Lumpur, Malaysia, 6-27 November 2013. 
180. Han, H.; Xu, H.; Yuan, Z.; Zhao, Y. State of charge estimation of li-ion battery in evs based on second-order sliding mode observer. In Proceedings of the IEEE Transportation Electrification Conference \& Expo 2014 (ITEC Asia-Pacific), Beijing, China, 31 August-3 September 2014.

181. Wang, W.; Chung, H.S.-H.; Zhang, J. Near-real-time parameter estimation of an electrical battery model with multiple time constants and soc-dependent capacitance. IEEE Trans. Power Electron. 2014, 29, 5905-5920. [CrossRef]

182. Afshari, H.H.; Attari, M.; Ahmed, R.; Farag, M.; Habibi, S. Modeling, parameterization, and state of charge estimation of li-ion cells using a circuit model. In Proceedings of the Transportation Electrification Conference and Expo (ITEC), Dearborn, MI, USA, 27-29 June 2016.

183. Yu, Z.; Xiao, L.; Li, H.; Zhu, X.; Huai, R. Model parameter identification for lithium batteries using the coevolutionary particle swarm optimization method. IEEE Trans. Ind. Electron. 2017, 64, 5690-5700. [CrossRef]

184. Hu, X.; Yuan, H.; Zou, C.; Li, Z.; Zhang, L. Co-estimation of state of charge and state of health for lithium-ion batteries based on fractional-order calculus. IEEE Trans. Veh. Technol. 2018, 67, 10319-10329. [CrossRef]

185. Aung, H.; Low, K.-S.; Soon, J.J. State-of-charge estimation using particle swarm optimization with inverse barrier constraint in a nanosatellite. In Proceedings of the Industrial Electronics and Applications (ICIEA), Auckland, New Zealand, 15-17 June 2015.

186. Ye, M.; Guo, H.; Cao, B. A model-based adaptive state of charge estimator for a lithium-ion battery using an improved adaptive particle filter. Appl. Energy 2017, 190, 740-748. [CrossRef]

187. Lai, X.; Yi, W.; Zheng, Y.; Zhou, L. An all-region state-of-charge estimator based on global particle swarm optimization and improved extended kalman filter for lithium-ion batteries. Electronics 2018, 7, 321. [CrossRef]

188. Salkind, A.J.; Fennie, C.; Singh, P.; Atwater, T.; Reisner, D.E. Determination of state-of-charge and state-of-health of batteries by fuzzy logic methodology. J. Power sources 1999, 80, 293-300. [CrossRef]

189. Singh, P.; Vinjamuri, R.; Wang, X.; Reisner, D. Design and implementation of a fuzzy logic-based state-of-charge meter for li-ion batteries used in portable defibrillators. J. Power Sources 2006, 162, 829-836. [CrossRef]

190. Malkhandi, S. Fuzzy logic-based learning system and estimation of state-of-charge of lead-acid battery. Eng. Appl. Artif. Intell. 2006, 19, 479-485. [CrossRef]

191. Li, I.-H.; Wang, W.-Y.; Su, S.-F.; Lee, Y.-S. A merged fuzzy neural network and its applications in battery state-of-charge estimation. IEEE Trans. Energy Convers. 2007, 22, 697-708. [CrossRef]

192. Yan, X.; Yang, Y.; Guo, Q.; Zhang, H.; Qu, W. Electric vehicle battery soc estimation based on fuzzy kalman filter. In Proceedings of the 2013 2nd International Symposium on Instrumentation and Measurement, Sensor Network and Automation (IMSNA), Toronto, ON, Canada, 23-24 December 2013.

193. Zhang, S.; Yang, L.; Zhao, X.; Qiang, J. A ga optimization for lithium-ion battery equalization based on soc estimation by nn and flc. Int. J. Electr. Power. Energy Syst. 2015, 73, 318-328. [CrossRef]

194. Li, Y.; Wang, C.; Gong, J. A combination kalman filter approach for state of charge estimation of lithium-ion battery considering model uncertainty. Energy 2016, 109, 933-946. [CrossRef]

195. Haykin, S.S. Neural Networks and Learning Machines; Pearson: Upper Saddle River, NJ, USA, 2009 ; Volume 3.

196. Affanni, A.; Bellini, A.; Concari, C.; Franceschini, G.; Lorenzani, E.; Tassoni, C. EV battery state of charge: Neural network based estimation. In Proceedings of the Electric Machines and Drives Conference (IEMDC'03), Madison, WI, USA, 1-4 June 2003.

197. Rui-hao, L.; Yu-kun, S.; Xiao-fu, J. Battery state of charge estimation for electric vehicle based on neural network. In Proceedings of the 2011 IEEE 3rd International Conference on Communication Software and Networks (ICCSN), Xi'an, China, 7-29 May 2011.

198. Charkhgard, M.; Farrokhi, M. State-of-charge estimation for lithium-ion batteries using neural networks and ekf. IEEE Trans. Ind. Electron. 2010, 57, 4178-4187. [CrossRef]

199. He, W.; Williard, N.; Chen, C.; Pecht, M. State of charge estimation for li-ion batteries using neural network modeling and unscented kalman filter-based error cancellation. Int. J. Electr. Power Energy Syst. 2014, 62, 783-791. [CrossRef]

200. Dong, G.; Zhang, X.; Zhang, C.; Chen, Z. A method for state of energy estimation of lithium-ion batteries based on neural network model. Energy 2015, 90, 879-888. [CrossRef]

201. Hussein, A.A. Derivation and comparison of open-loop and closed-loop neural network battery state-of-charge estimators. Energy Procedia 2015, 75, 1856-1861. [CrossRef] 
202. Wang, Y.; Yang, D.; Zhang, X.; Chen, Z. Probability based remaining capacity estimation using data-driven and neural network model. J. Power Sources 2016, 315, 199-208. [CrossRef]

203. Hussein, A.A. Capacity fade estimation in electric vehicle li-ion batteries using artificial neural networks. IEEE Trans. on Ind. Appl. 2015, 51, 2321-2330. [CrossRef]

204. Tong, S.; Lacap, J.H.; Park, J.W. Battery state of charge estimation using a load-classifying neural network. J. Energy Storage 2016, 7, 236-243. [CrossRef]

205. Dang, X.; Yan, L.; Xu, K.; Wu, X.; Jiang, H.; Sun, H. Open-circuit voltage-based state of charge estimation of lithium-ion battery using dual neural network fusion battery model. Electrochimica Acta 2016, 188, 356-366. [CrossRef]

206. Chaoui, H.; Ibe-Ekeocha, C.C.; Gualous, H. Aging prediction and state of charge estimation of a lifepo4 battery using input time-delayed neural networks. Electric Power Syst. Res. 2017, 146, 189-197. [CrossRef]

207. Shi, Q.; Zhang, C.; Cui, N.; Zhang, X. Battery state-of-charge estimation in electric vehicle using elman neural network method. In Proceedings of the 29th Chinese Control Conference (CCC), Beijing, China, 29-31 July 2010.

208. Kang, L.; Zhao, X.; Ma, J. A new neural network model for the state-of-charge estimation in the battery degradation process. Appl. Energy 2014, 121, 20-27. [CrossRef]

209. Guo, Y.; Zhao, Z.; Huang, L. Soc estimation of lithium battery based on improved bp neural network. Energy Procedia 2017, 105, 4153-4158. [CrossRef]

210. Cui, D.; Xia, B.; Zhang, R.; Sun, Z.; Lao, Z.; Wang, W.; Sun, W.; Lai, Y.; Wang, M. A novel intelligent method for the state of charge estimation of lithium-ion batteries using a discrete wavelet transform-based wavelet neural network. Energies 2018, 11, 995. [CrossRef]

211. Hannan, M.A.; Lipu, M.S.H.; Hussain, A.; Saad, M.H.; Ayob, A. Neural network approach for estimating state of charge of lithium-ion battery using backtracking search algorithm. IEEE Access 2018, 6, 10069-10079. [CrossRef]

212. Chen, Z.; Qiu, S.; Masrur, M.A.; Murphey, Y.L. Battery state of charge estimation based on a combined model of extended kalman filter and neural networks. In Proceedings of the 2011 International Joint Conference on Neural Networks (IJCNN), San Jose, CA, USA, 31 July-5 August 2011.

213. Shen, W.; Chan, C.C.; Lo, E.W.; Chau, K. Adaptive neuro-fuzzy modeling of battery residual capacity for electric vehicles. IEEE Trans. Ind. Electron. 2002. [CrossRef]

214. Cai, C.; Du, D.; Liu, Z. Battery state-of-charge (soc) estimation using adaptive neuro-fuzzy inference system (anfis). In Proceedings of the 12th IEEE International Conference on Fuzzy Systems (FUZZ'03), St. Louis, MO, USA, 25-28 May 2003.

215. Chau, K.; Wu, K.; Chan, C. A new battery capacity indicator for lithium-ion battery powered electric vehicles using adaptive neuro-fuzzy inference system. Energy Convers. Manag. 2004, 45, 1681-1692. [CrossRef]

216. Fotouhi, A.; Propp, K.; Auger, D.J. Electric vehicle battery model identification and state of charge estimation in real world driving cycles. In Proceedings of the 7th Computer Science and Electronic Engineering Conference (CEEC), University of Essex, Essex, UK, 24-25 September 2015.

217. Dai, H.; Guo, P.; Wei, X.; Sun, Z.; Wang, J. Anfis (adaptive neuro-fuzzy inference system) based online soc (state of charge) correction considering cell divergence for the EV (electric vehicle) traction batteries. Energy 2015, 80, 350-360. [CrossRef]

218. Awadallah, M.A.; Venkatesh, B. Accuracy improvement of soc estimation in lithium-ion batteries. J. Energy Storage 2016, 6, 95-104. [CrossRef]

219. Wu, X.; Mi, L.; Tan, W.; Qin, J.L.; Zhao, M.N. State of charge (soc) estimation of ni-mh battery based on least square support vector machines. In Advanced Materials Research; Trans Tech Publications: Stafa-Zurich, Sweitzerland, 2011; pp. 1204-1209.

220. Antón, J.Á.; Nieto, P.G.; de Cos Juez, F.; Lasheras, F.S.; Vega, M.G.; Gutiérrez, M.R. Battery state-of-charge estimator using the svm technique. Appl. Math. Model. 2013, 37, 6244-6253. [CrossRef]

221. Anton, J.A.; Nieto, P.G.; Viejo, C.B.; Vilan, J.V. Support vector machines used to estimate the battery state of charge. IEEE Trans. Power Electron. 2013, 28, 5919-5926. [CrossRef]

222. Chen, Y.; Long, B.; Lei, X. The battery state of charge estimation based weighted least squares support vector machine. In Proceedings of the 2011 Asia-Pacific Power and Energy Engineering Conference (APPEEC), Wuhan, China, 25-28 March 2011. 
223. Hu, J.; Hu, J.; Lin, H.; Li, X.; Jiang, C.; Qiu, X.; Li, W. State-of-charge estimation for battery management system using optimized support vector machine for regression. J. Power Sources 2014, 269, 682-693. [CrossRef]

224. Sheng, H.; Xiao, J. Electric vehicle state of charge estimation: Nonlinear correlation and fuzzy support vector machine. J. Power Sources 2015, 281, 131-137. [CrossRef]

225. Friedman, J.H. Multivariate adaptive regression splines. Annals Stat. 1991, 1-67. [CrossRef]

226. Antón, J.C.Á.; Nieto, P.J.G.; de Cos Juez, F.J.; Lasheras, F.S.; Viejo, C.B.; Gutiérrez, N.R. Battery state-of-charge estimator using the mars technique. IEEE Trans. Power Electron. 2013, 28, 3798-3805. [CrossRef]

227. Antón, J.C.Á.; Nieto, P.J.G.; Gonzalo, E.G.; Pérez, J.C.V.; Vega, M.G.; Viejo, C.B. A new predictive model for the state-of-charge of a high-power lithium-ion cell based on a pso-optimized multivariate adaptive regression spline approach. IEEE Trans. Veh. Technol. 2016, 65, 4197-4208. [CrossRef]

C 2019 by the authors. Licensee MDPI, Basel, Switzerland. This article is an open access article distributed under the terms and conditions of the Creative Commons Attribution (CC BY) license (http:/ / creativecommons.org/licenses/by/4.0/). 